\title{
THE SHORT-RUN, DYNAMIC EMPLOYMENT EFFECTS OF NATURAL DISASTERS: NEW INSIGHTS
}

ALESSANDRO BARATTIERI PATRICE BORDA ALBERTO BRUGNOLI MARTINO PELLI JEANNE TSCHOPP 




Center for Interuniversity Research and Analysis on Organizations

The purpose of the Working Papers is to disseminate the results of research conducted by CIRANO research members in order to solicit exchanges and comments. These reports are written in the style of scientific publications. The ideas and opinions expressed in these documents are solely those of the authors.

Les cahiers de la série scientifique visent à rendre accessibles les résultats des recherches effectuées par des chercheurs membres du CIRANO afin de susciter échanges et commentaires. Ces cahiers sont rédigés dans le style des publications scientifiques et n'engagent que leurs auteurs.

CIRANO is a private non-profit organization incorporated under the Quebec Companies Act. Its infrastructure and research activities are funded through fees paid by member organizations, an infrastructure grant from the government of Quebec, and grants and research mandates obtained by its research teams.

Le CIRANO est un organisme sans but lucratif constitué en vertu de la Loi des compagnies du Québec. Le financement de son infrastructure et de ses activités de recherche provient des cotisations de ses organisations-membres, d'une subvention d'infrastructure du gouvernement du Québec, de même que des subventions et mandats obtenus par ses équipes de recherche.

\section{CIRANO Partners - Les partenaires du CIRANO}

Corporate Partners - Partenaires corporatifs

Autorité des marchés financiers

Bank of Canada

Bell Canada

BMO Financial Group

Business Development Bank of Canada

Caisse de dépôt et placement du Québec

Desjardins Group

Énergir

Hydro-Québec

Innovation, Science and Economic Development Canada

Intact Financial Corporation

Manulife Canada

Ministère de l'Économie, de la Science et de l'Innovation

Ministère des finances du Québec

National Bank of Canada

Power Corporation of Canada

PSP Investments

Rio Tinto

Ville de Montréal

Academic Partners - Partenaires universitaires

Concordia University

École de technologie supérieure

École nationale d'administration publique

HEC Montréal

McGill University

National Institute for Scientific Research

Polytechnique Montréal

Université de Montréal

Université de Sherbrooke

Université du Québec

Université du Québec à Montréal

Université Laval

CIRANO collaborates with many centers and university research chairs; list available on its website. Le CIRANO collabore avec de nombreux centres et chaires de recherche universitaires dont on peut consulter la liste sur son site web.

(C) June 2021. Alessandro Barattieri, Patrice Borda, Alberto Brugnoli, Martino Pelli, Jeanne Tschopp. All rights reserved. Tous droits réservés. Short sections may be quoted without explicit permission, if full credit, including $\mathbb{C}$ notice, is given to the source. Reproduction partielle permise avec citation du document source, incluant la notice (C)

The observations and viewpoints expressed in this publication are the sole responsibility of the authors; they do not necessarily represent the positions of CIRANO or its partners. Les idées et les opinions émises dans cette publication sont sous l'unique responsabilité des auteurs et ne représentent pas nécessairement les positions du CIRANO ou de ses partenaires. 


\title{
The Short-Run, Dynamic Employment Effects of Natural Disasters: New Insights*
}

\author{
Alessandro Barattieri ${ }^{\dagger} \quad$ Patrice Borda ${ }^{\ddagger} \quad$ Alberto Brugnoli $\S$ \\ Martino Pelli ฯ Jeanne Tschopp"
}

June 2021

\begin{abstract}
We study the short-run, dynamic employment effects of natural disasters. We exploit monthly data for over 90 3-digits NAICS industries and 78 Puerto Rican counties over the period 1995-2017. Our exogenous measure of exposure to natural disasters is computed using the maximum wind speed recorded in each county during each hurricane. Using panel local projections, we find that after the "average" hurricane, employment and wages fall by $1 \%$ on average. The effects peak after six months and disappear within two years. Across industries, we find substantial heterogeneity in the employment responses. This heterogeneity can be partly explained by input-output linkages.
\end{abstract}

Keywords: Natural Disasters, Employment, High-Frequency Data, Local Projections JEL Codes: Q54, E24.

${ }^{*}$ We are grateful to the Social Sciences and Humanities Research Council (SSHRC) for its financial support (grant number 039367). We would like to thank Matias Cortes, Etienne Lalé, Ben Sand, Charles Seguin, Eric Strobl and participants at various conferences and presentations for useful comments and suggestions. All errors are ours.

${ }^{\dagger}$ ESG UQAM. Mail: Case Postale 8888, sucursale Centre-ville Montreal (Quebec) H3C 3P8, Canada; barattieri.alessandro@uqam.ca.

${ }^{\ddagger}$ Université des Antilles, UFR des Sciences Juridiques et Economiques Campus de Fouillole - BP 270 97157 Pointe-Pitre, Guadeloupe; patrice.borda@univ-antilles.fr.

${ }^{\S}$ University of Bergamo, Department of Economics. Via dei Caniana 2 - 24127, Bergamo, Italy; alberto.brugnoli@unibg.it.

ฯUniversity of Sherbrooke, Department of Economics, 2500 Blvd de l'Université, Sherbrooke, Q.C., Canada, CIREQ, CIRANO, and GREDI; Martino.Pelli@USherbrooke.ca.

"University of Bern, Department of Economics, Schanzeneckstrasse 1, 3001 Bern, Switzerland; jeanne.tschopp@vwi.unibe.ch. 


\section{Introduction}

In 2020, for only the second time in history, the World Meteorological Organization ran out of letters to name the Atlantic tropical storms, and started using names from the Greek alphabet. ${ }^{1}$ Moreover, natural disasters are expected to increase reported direct losses from the current $\$ 195$ billion a year to $\$ 234$ billion a year by 2040 . This increase of $\$ 39$ billion could reach up to $\$ 100$ billion per year if the indirect costs from supply chain disruption and other knock-on economic consequences are factored in. ${ }^{2}$ Given these facts, it is hardly surprising that studying the economic consequences of climate change and natural disasters has become a central research question in several fields of economics. However, due to data availability, and especially in the context of less developed regions, there has been so far no evidence coming from high frequency, detailed industry data. This is relevant, because detailed data can help uncover the economic mechanisms taking place in the aftermath of a hurricane. As a first step towards filling this gap, in this paper we study the short-run, dynamic employment effects of natural disasters using an ideal laboratory: Puerto Rico.

We exploit a unique feature of Puerto Rico: a frequent exposure to natural disasters, combined with the availability of high frequency, detailed employment data. This combination allows us to propose the first estimates of the short-run, dynamic employment effects of hurricanes using geo-coded monthly data for over 90 3-digits NAICS industries, and 78 counties over the period 1995-2017. We also study the impact of hurricanes on wages at quarterly frequency.

With the aid of satellite data, we are able to track the position of the eye of each storm and the wind speed within it at six-hours intervals. Due to the precise laws of physics, this information is sufficient to compute the wind speed at any distance from the storm's eye. We are therefore able to measure the intensity of natural disasters in all of Puerto Rico's counties, by using the maximum wind speed recorded in each county cell during each storm. Exploiting information on wind speed guarantees the absence of any potential endogeneity of our measure with respect to economic outcomes, which can lead to biased results, as shown by Felbermayr \& Gröschl (2014). Armed with this exogenous measure of exposure to natural disasters, varying over time and at the county level, we explore the dynamic employment effects of natural disasters using local projections. This tool, which has now been used in many contexts, consists of running a sequence of regressions for different prediction horizons.

\footnotetext{
1"With \#Alpha, 2020 Atlantic Tropical Storm Names Go Greek", NOAA News, 17 September 2020. https://www.noaa.gov/news/with-alpha-2020-atlantic-tropical-storm-names-go-greek.

2"Natural Disasters Could Cost 20 Percent More By 2040 Due to Climate Change," E360 digest 27, 2020, Yale University. https://e360.yale.edu/digest/ natural-disasters-could-cost-20-percent-more-by-2040-due-to-climate-change.
} 
One advantage of local projections is that, unlike panel VARs, they do not impose (potentially incorrect) dynamic restrictions. We regress the cumulative change of our variables of interest (employment and average weekly wages) on our disaster shock variable at each horizon. The coefficients obtained trace the dynamic responses of employment and wages to a disaster shock. The richness of our data allows us to include in the main specification a full set of industry (3-digits NAICS), counties and time fixed effects. In one specification, focusing on a reduced sample starting in 2010, we are also able to control for the county-level evolution of population, which allows us to control for potential changes in labor supply. We also propose the results we obtained for each industry, after controlling for seasonal and aggregate effects.

We find three main results. First, after the "average" hurricane, employment falls on average by about $1 \%$, and so do average weekly wages. The effects peak after about six months and they disappear within two years. Second, we find very heterogeneous effects across industries. In some industries, which we call the "strengthened industries", employment increases following a natural disaster. Examples of these industries include NAICS 236 ("Construction of Buildings')' and NAICS 238 ("Specialty trade contractors"). In other industries, which we call "weakened" industries, employment decreases. Examples of weakened industries are NAICS 721 ("Accommodation") and NAICS 487 ("Scenic and Sightseeing Transportation"). In a third group of industries, employment does not seem to be directly affected by natural disasters. We call them "neutral" industries. Most of the manufacturing sector falls in the third category. Finally, we uncover a potential mechanism that can explain some of the results at the industry level: input-output linkages. The construction boom, for instance, is the likely trigger of the increase in employment in the manufacturing of furniture and of metal products. According to the 2019 BEA I-O tables for the US, in fact, construction is by far the most important buyer for both of these sectors.

Finally, the heterogeneous cyclicality of employment to hurricanes across different industries suggests a new concept of resilience to natural disaster shocks: adaptability-driven employment resilience, defined as the potential ability of workers to rapidly reallocate from the contracting industries to the expanding ones in the aftermath of a natural disaster. This could be an important building block of the "post-disaster resilience", which was included as one of the three pillars of the "disaster resilience strategy" framework proposed by the IMF (2019). Adaptability-driven employment resilience could potentially be achieved (or enhanced) by introducing new and different vocational training programs, aimed at endowing workers with a set of heterogeneous skills, which are needed for rapid and temporary reallocations across different industries.

The remainder of the paper is structured as follows. After a brief overview of the relevant literature, Section 2 presents the data, particularly our measure of exposure to natural 
disasters. In Section 3 we discuss our empirical strategy, and Section 4 contains the results. Finally, Section 5 concludes.

\subsection{Related literature}

First, this paper is linked to the literature exploring the effects of natural disasters on a variety of different outcomes, such as economic growth (Hsiang \& Jina, 2014; Felbermayr \& Gröschl, 2014; Bertinelli \& Strobl, 2013; Cavallo et al., 2013; Strobl, 2011), firm level outcomes (Pelli et al., 2020; Elliott et al., 2019; Seetharam, 2018; Vu \& Noy, 2018), exports (Pelli \& Tschopp, 2017), household finance (Deryugina et al., 2018; Gallagher \& Hartley, 2017), education (Sacerdote, 2012), housing (Ortega \& Taspinar, 2018) and migration (Boustan et al., 2020). Some papers have looked more closely at the employment effects of natural disasters. Belasen \& Polachek (2008) explore the employment effects of hurricanes in Florida for the period 1988-2005 using a difference in difference approach. McIntosh (2008) presents an event study of the impact of the migration induced by Hurricane Katrina on the local labor market in Houston. Groen \& Polivka (2008) study the labor market outcome of the people evacuated from hurricane Katrina. Kirchberger (2017) studies the effects of a large earthquake in Indonesia on the wage dynamics across different sectors, while Groen et al. (2020) look at the long-term employment outcomes of the workers affected by hurricanes Katrina and Rita. None of these studies combines our measure of exposure to (frequent) natural disasters to our analysis of their short-run, dynamic employment effects at a detailed industry level.

Second, our paper is linked to the literature using local projections to investigate the dynamic effects of shocks on the economy, following the seminal work by Jorda (2005). Examples of this literature include Auerbach \& Gorodnichenko (2013), Jorda \& Taylor (2016), and Leduc \& Wilson (2013), who look at fiscal policy shocks. Ottonello \& Winberry (2020) investigates the effects of monetary shocks, while Barattieri \& Cacciatore (2020) study trade policy shocks in the presence of network effects. We apply this econometric tool for the first time to the study of the employment effects of natural disasters shocks.

Finally, our paper is linked to the literature exploring features of the Puerto Rican economy, and especially the impact of hurricane Maria. Lugo (2019) studies the social and technological effects of Maria. Watkins et al. (2020) look at health outcomes, while Peri et al. (2020) study the labor market effects in Orlando of the inflow of immigrants from Puerto Rico following hurricane Maria. 


\section{Data}

In this Section we introduce both our measure of exposure to natural disasters, obtained using satellite data, and the data on Puerto Rican employment dynamics taken from the Bureau of Labor Statistics (BLS).

\subsection{Wind speed at the county level}

We use satellite data from the National Oceanic and Atmospheric Administration (NOAA) Tropical Prediction Center. We look at the storms' best tracks in the Caribbean Sea over the period 1995-2017, to construct the maximum wind speed associated with each hurricane $H$ hitting Puerto Rican county $c$, i.e. $w_{c H}$. A best track contains the full history of a hurricane, with information at 6-hours intervals on latitude, longitude, date and wind speed at its eye.

First, we linearly interpolate the storms' best tracks at every kilometer. For each interpolated kilometer, we obtain the set of coordinates for the position of the eye (landmark $h$ ) and the wind speed at the eye, $V_{h}$. For each county that falls in the vortex associated with a landmark $h$, we use the HURRECON model (see Boose et al., 1994, 2001, 2004) to compute the sustained wind velocity at the county's centroid, $w_{c h}{ }^{3}$

In order to improve the precision of our measure and obtain a good proxy of the impact of hurricanes on economic activity, we do not use the simple geometrical centroid of each county. Instead, using population data from the 2010 Census at the block level and the geometrical centroid of each census block, we construct a population weighted centroid for each of the 78 counties of Puerto Rico. This correction allows us to compute the maximum wind speed affecting populated areas and to give less weight to strong winds hitting forests or other areas with no economic activity.

Finally, we obtain one measure of windspeed per county and hurricane by retaining the maximum windspeed to which a county was exposed:

$$
w_{c H}=\max _{h \in H}\left\{w_{c h}\right\}
$$

\subsection{Counties exposure to hurricanes}

In what follows we describe how we construct $S_{c t}$, the index of exposure to hurricanes of county $c$ at time $t$ (where time can be at monthly or quarterly frequency). Following Bernabe et al. (2021), Pelli et al. (2020), Pelli \& Tschopp (2017), and Yang (2008), our index of

\footnotetext{
${ }^{3}$ More details about the HURRECON model are provided in Appendix A.1.
} 
exposure is obtained in the following way:

$$
S_{c t}=\sum_{H} x_{c H t} \quad \text { where } \quad x_{c H t}=\frac{\left(w_{c H t}-33\right)^{3}}{\left(w^{\max }-33\right)^{3}} \quad \text { if } \quad w_{c H t}>33
$$

where $x_{c H t}$ represents the maximum windspeed affecting county $c$ during storm $H$ at time $t$ relative to the sample maximum (the term $w^{\max }$ ). We normalize the index with respect to the maximum wind speed observed in order to obtain a measure included between zero and one. The cubic powers account for the force exerted by winds on physical structures (see the technical HAZUS manual of the Federal Emergency Management Agency (FEMA) of the US Department of Homeland Security and Emanuel, 2005). ${ }^{4}$ We use a threshold of 33 knots, which defines a tropical storm according to the Simpson and Riehl scale. ${ }^{5,6}$

Figure 1 shows examples of our measure of exposure for four major hurricanes that hit Puerto Rico over the years. On the left side of the figure we show the best track for each of the four hurricanes while, on the right side, we show the exposure index, $S_{c t}$, for each of the four months concerned. This figure underlines the large extent of geographical and time variation at our disposal for identification. Hurricanes Jeanne, for instance, hit mostly the western part of Puerto Rico (the counties most affected were municipios "Aguada", "Aguadilla" and "Cabo Rojo"). On the contrary, hurricanes Irene and Maria hit much more severely the eastern part of the island. Municipios "Vieques", "Yabucoa" and "Culebra" were the counties most affected by hurricane Irene, while municipios "Culebra", "Fajardo" and "Luquillo" were the counties most affected by hurricane Maria. Finally, hurricane George hit mostly the central part of the island. The counties most affected were municipios "Catano", "Aibonito", and "Toa Alta". In the Online Appendix, we list the 23 hurricanes and storms that hit Puerto Rico in our sample period.

\subsection{Puerto Rico Employment Data}

We use employment data from the Quarterly Census of Employment and Wages (QCEW) by the Bureau of Labor Statistics of the United States (BLS). The QCEW contains monthly data on employment and quarterly data on wages at the county-industry level. We focus our attention on employment in the private sector. To give a broad idea of the economic

\footnotetext{
${ }^{4}$ In the Online Appendix we experiment with a variety of alternative specifications of counties exposure to hurricanes.

${ }^{5}$ In one robustness check, we increase the threshold from 33 knots to 64 .

${ }^{6}$ By definition, $S_{c t} \in\left(0, \sum_{H}\right)$, with a value of 0 indicating zero county exposure to hurricanes (i.e. winds in county $c$ are below the threshold) and with $\sum_{H}$ indicating the number of storms hitting a county at time $t$. This is because in the cases when more that one hurricane hits Puerto Rican counties at the same time $t$, we sum $x_{c H t}$ over hurricanes.
} 


\section{Figure 1: County Exposure to Hurricanes - Examples}

Hurricane Georges (September 1998)

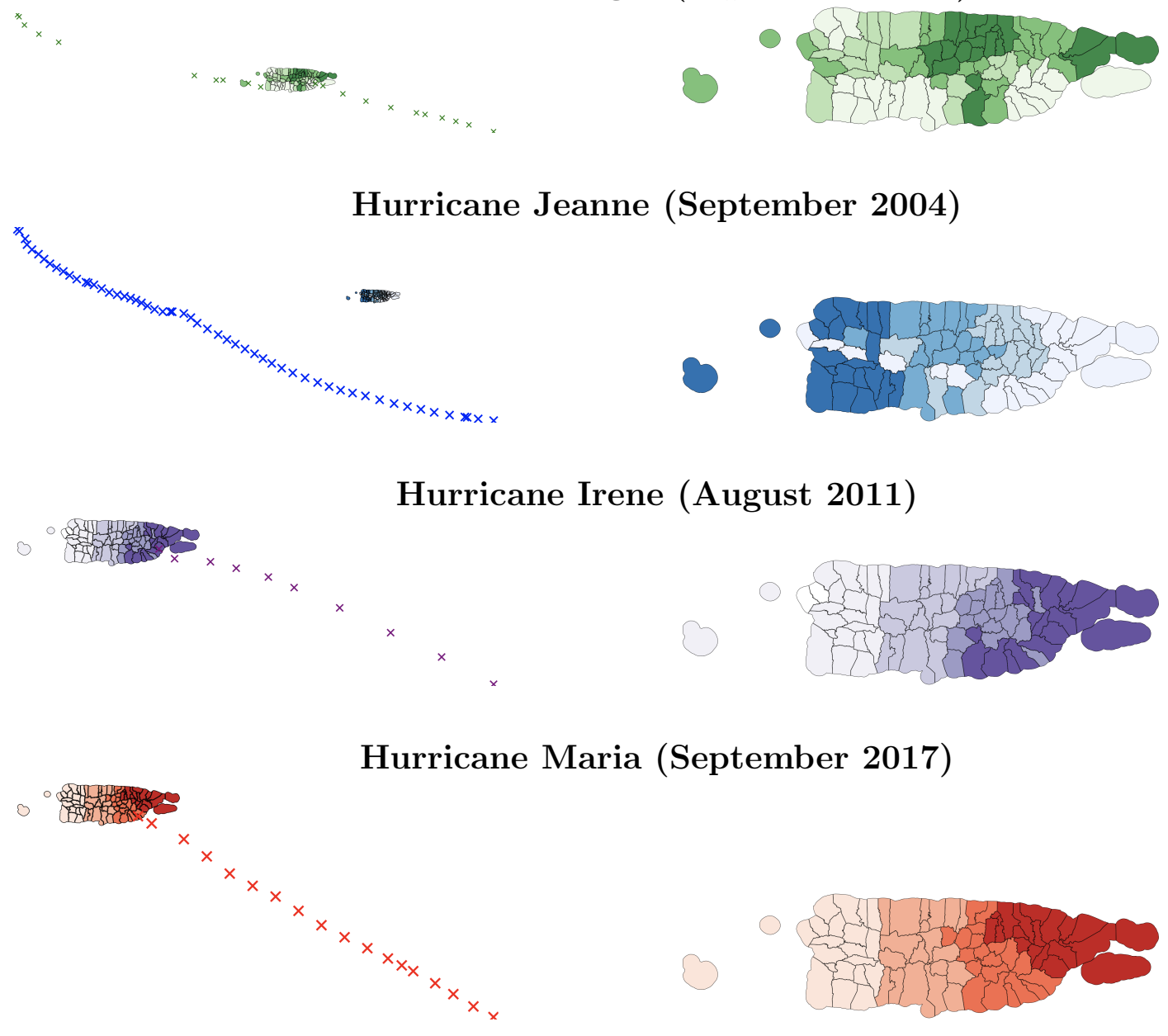

structure of the Puerto Rican economy, during our sample period, the private sector employed on average 674,800 people. Of those workers, $18.4 \%$ were employed in Retail Trade (NAICS 44-45), 17.2\% in Manufacturing (NAICS 30), 9.7\% in Health care and social assistance (NAICS 62), 9.1\% in Accommodation and Food Services (NAICS 72), 8.7\% in the Administrative and Waste services (NAICS 46), and 7.1\% in Construction (NAICS 23). In terms of employment dynamics, manufacturing has witnessed a secular decline. Most services display an increase over time, while the construction sector seems characterized by an inverted U-shaped dynamics.

Within the manufacturing sector, the most important industries in terms of average employment in our sample period are NAICS 325 ("Chemical manufacturing"), NAICS 311 ("Food manufacturing"), and NAICS 315 ("Apparel manufacturing"). While (unsurprisingly) apparel manufacturing employment displays a negative trend, chemical manufacturing em- 
ployment shows an inverted-U shape. In the Online Appendix, we provide tables and graphs with more details on the structure of the Puerto Rican economy.

\section{Empirical Strategy}

Armed with the exogenous exposure to natural disaster shocks illustrated in the previous section, we explore the dynamic employment effects of natural disasters using local projections. After the seminal contribution by Jorda (2005), local projections have become a tool used in many settings, as discussed in the introduction. The approach consists of running a sequence of predictive regressions of a variable of interest on a shock for different prediction horizons. The sequence of regression coefficients traces the dynamic response of the variable of interest to the shock. The main advantages of this approach are that local projections do not impose potentially inappropriate dynamic restrictions (as panel VARS do), they are robust to misspecification of the data generating process, and they can be estimated in a simple univariate framework.

In our context, for our main specification, we run the following $k$-step ahead panel predictive regressions:

$$
\Delta X_{i c, t+k}=\alpha^{k}+\gamma^{k} S_{c t}+\delta_{t}+\nu_{i}+\eta_{c}+\epsilon_{i c, t+k}
$$

where $\Delta X_{i c, t+k}$ is the cumulative growth of our variable of interest from time $t-1$ to time $t+k$ (that is, $\Delta X_{i c, t+k} \equiv \log X_{i c, t+k}-\log X_{i c, t-1}$ ). $X$ represents either employment (for each industry $i$ and county $c$ at monthly frequency) or the average weekly wage (for each industry $i$ and county $c$ at quarterly frequency). $S_{c t}$ is our measure of disaster shocks, varying at county level for each month (or quarter). Our object of interest is $\gamma^{k}$, representing the average response of $X$ at horizon $k$ to a disaster shock at time $t$. Our sample period run from 1995M1 to 2017M11. We have data for a panel of 93 NAICS3 industries and 78 counties (GEO). The richness of our data allows us to also include time, NAICS3 and GEO fixed effects (respectively $\delta_{t}, \nu_{i}$, and $\eta_{c}$ ). We also experiment with alternative sets of fixed effects (using GEO-NAICS3 and time or GEO and NAICS3-time fixed effects). Finally, we restrict our attention to a more recent sample (from 2010) where we can insert as a further control variable the cumulative growth of the population from time $t-1$ to time $t+k$ for each county $c\left(\Delta P o p_{i c, t+k}\right){ }^{7}$ This extra control allows us to proxy for the evolution of labor

\footnotetext{
${ }^{7}$ Population estimates are provided by the US Census for each Puerto Rican county at yearly frequency starting in 2010. In order to compute our monthly (or quarterly) frequency control variables, we linearly interpolate the annual population estimates. In the Online Appendix, we provide information on the structure of the Puerto Rican population in 2010 and its dynamics over time. On average, Puerto Rican counties saw
} 
supply.

We also explore the dynamic employment effects at the level of each single industry. The analog of equation 2 now becomes:

$$
\Delta X_{i, t+k}=\alpha^{k}+\gamma_{i}^{k} S_{t}+\beta^{k} \Delta X_{t+k}^{A G G R}+\delta_{m}\left(\delta_{q}\right)+\epsilon_{i, t+k}
$$

In this case, we do not exploit the variation at the county level, but only at the industry level. As before, $X$ represents either employment (for each industry $i$ at monthly frequency) or the average weekly wage (for each industry $i$ at quarterly frequency). $S_{t}$ is an aggregate measure of exposure to disaster, computed as a population-weighted average of $S_{c t}$. Our object of interest is $\gamma_{i}^{k}$, representing the response of $X_{i}$ at horizon $k$ to a disaster shock at

time $t$. In order to control for aggregate effects, we also insert in the regression $X^{A G G R}$, which is a measure of the aggregate counterpart of $X$. Finally, while we cannot use a full set of time fixed effects, as in equation 2 , we insert instead $\delta_{m}\left(\delta_{q}\right)$, which are monthly (quarterly) dummies, to control for potential seasonal effects.

In the next Section, we report impulse responses following a disaster shock. This means that we plot the coefficients $\gamma^{k}$ and $\gamma_{i}^{k}$ at different horizons $k$, together with their $90 \%$ confidence intervals. We consider a two years horizon. Therefore, at monthly frequency $k$ ranges from 0 to 24 , while at quarterly frequency $k$ ranges from 0 to 8.

\section{Results}

Figure 2 reports our main results. In the first row, we report the coefficients obtained from equation 2. As the Figure shows, after the "average" hurricane, employment falls on average by about $1 \%$, and so do average weekly wages. The effects peak after about six months and they disappear within two years. The effects are strongly statistically significant for employment and borderline significant for average weekly wages. In the second and third row of Figure 2, we report the results we obtain using different specifications for the fixed effects in equation 2. In the second row, we report the results obtained if we substitute the GEO and industry fixed effects $\left(\eta_{c}\right.$ and $\left.\nu_{i}\right)$ with a combined GEO-industry fixed effect $\left(\eta_{c i}\right)$. In the third row, we instead substitute the industry and time fixed effects $\left(\delta_{t}\right.$ and $\left.\nu_{i}\right)$ with a combined industry-time fixed effect $\left(\delta_{i t}\right)$. As the Figure shows, the results are very similar to our baseline specification. ${ }^{8}$ Finally, in the fourth row of Figure 2, we report a robustness test based on a more recent sample (post 2010), in which we can add as control also the

a loss of population of about $10 \%$ during the period 2010-2017.

${ }^{8}$ Clearly the third possible option, combining $\eta_{c}$ and $\delta_{t}$, would prevent us from estimating the coefficients of interest $\gamma^{k}$, since $S_{c t}$ would be absorbed by the county-time fixed effects. 
cumulative growth of the population at county-level. As the Figure shows, our main results are robust also to this alternative specification, which accounts for potential changes in the labor supply.

\section{Figure 2: Employment Effects of Natural Disasters: Panel Results}
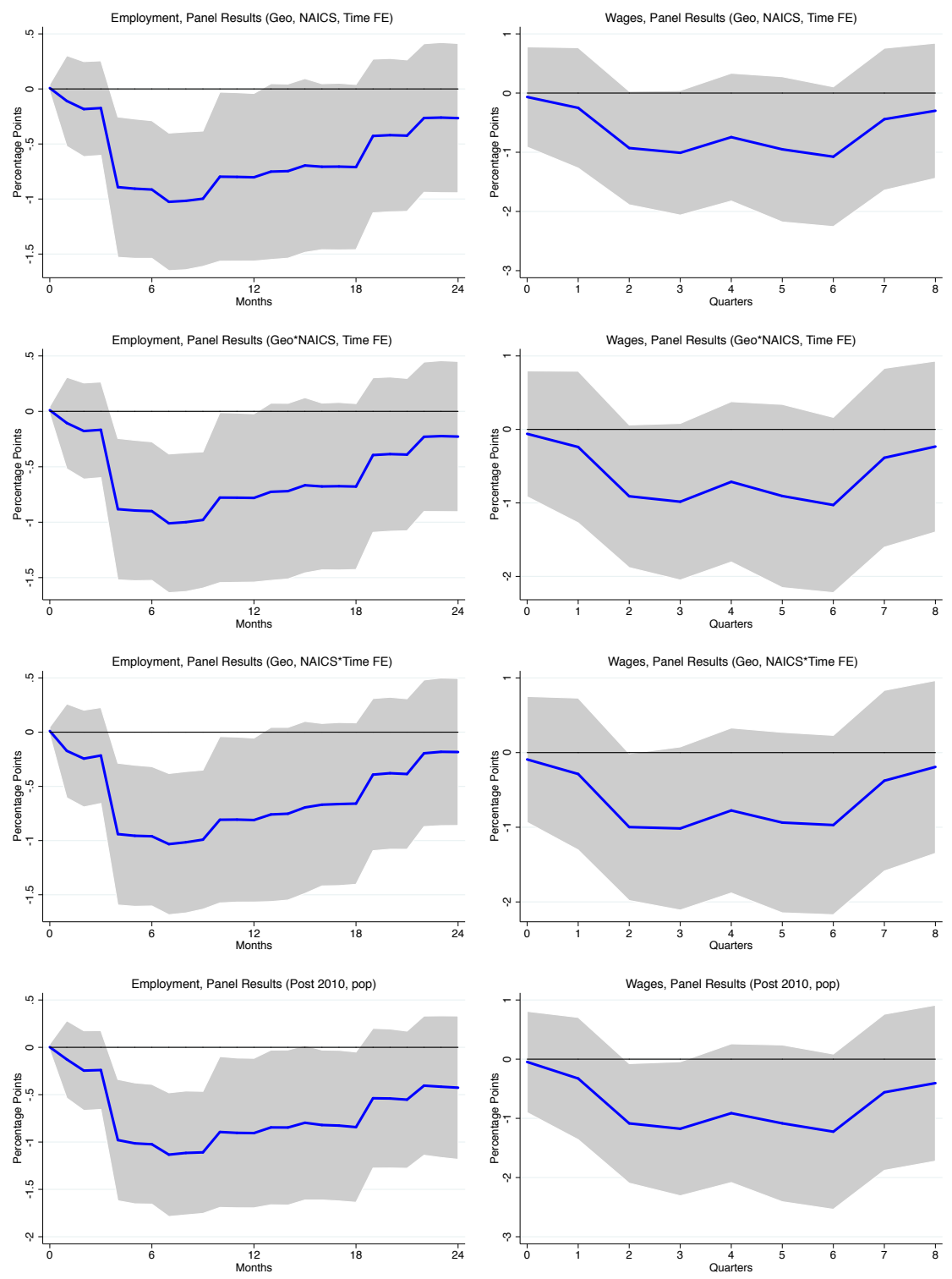

We then move to explore whether this average effect masks heterogeneous responses across industries. Using specification 3, we find that industries can be divided into three main groups. A first group of industries, which we call "strengthened", is reported in Figure 3. 
Figure 3: Employment Effects of Natural Disasters: Strengthened Industries
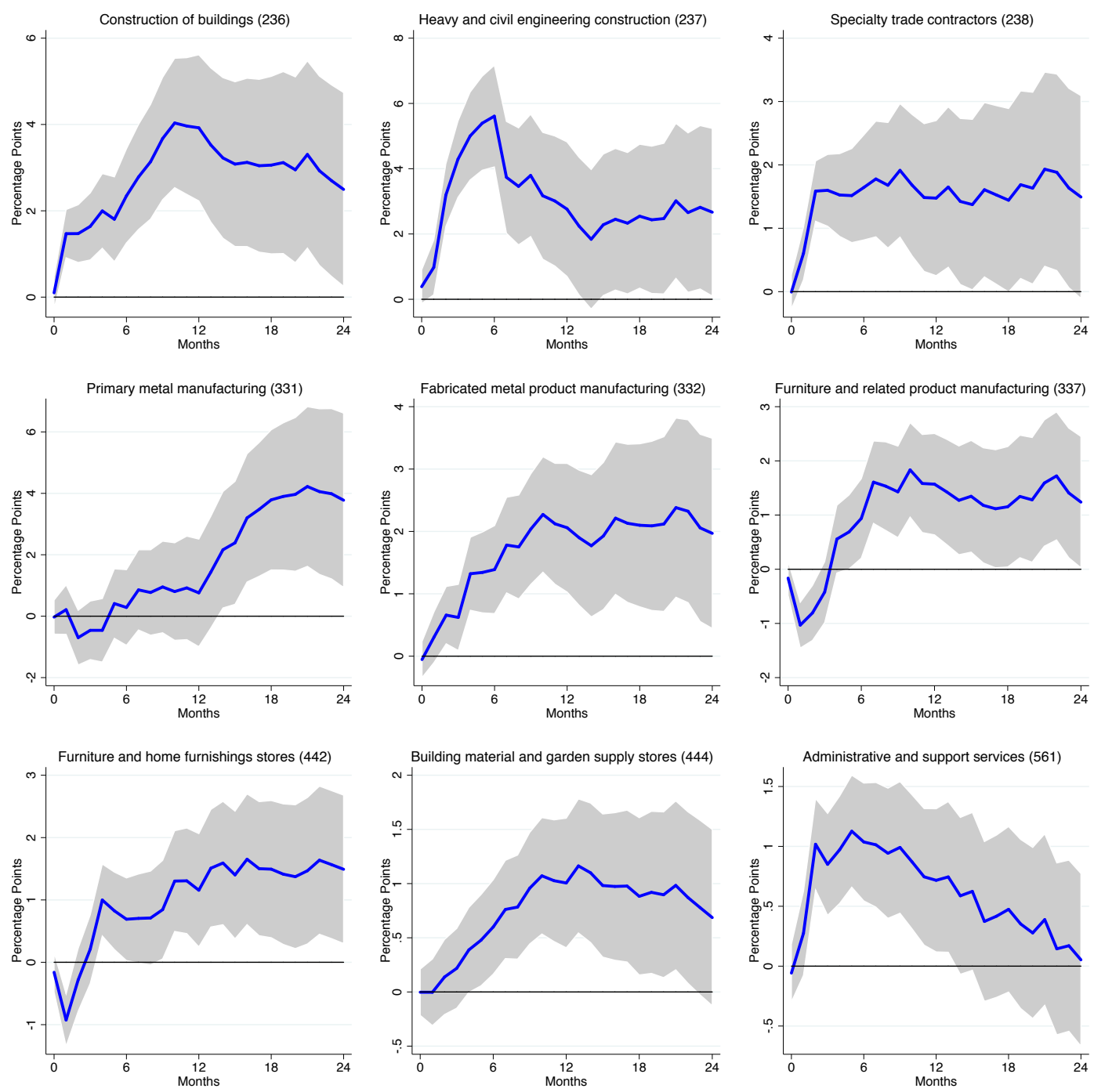

These are the nine industries that experience an increase in employment following a disaster shock. In the first row, the Figure illustrates a clear (and sensible) boom in construction: in industries NAICS 236 ("Construction of buildings"), NAICS 237 ("Heavy and civil engineering constructions") and NAICS 238 ("Special trade contractors") employment grows by between $2 \%$ and $5 \%$ after 6 months following the "average" hurricane. In the second row of Figure 3, we report the three manufacturing industries that experience an expansion in employment after a disaster shock: NAICS 331 ("Primary metal manufacturing"), NAICS 332 ("Fabricated metal product manufacturing"), and NAICS 337 ("Furniture Manufacturing"). Interestingly, the increase appears delayed in the case of furniture manufacturing. 
Finally, there are three service sector industries that see an increase in employment after an hurricane, as reported by the third row in Figure 3: NAICS 442 ("Furniture and home furniture stores"), NAICS 444 ("Building material and garden supply stores"), and NAICS 561 ("Administrative and support services"). In the Online Appendix, we report the impulse response of average weekly wages for the nine strengthened industries. Wages responses tend to be non-statistically significant, with the exception of sectors NAICS 237 ("Heavy and civil engineering constructions") and NAICS 238 ("Special trade contractors"), where we found a large and statistically significant increase of the average weekly wage.

A second group of industries is reported in Figure 4. These industries, which we label "weakened" industries, experience a fall in employment following a disaster shock. The first row reports the results for primary and manufacturing weakened industries: NAICS 111 ("Crop production"), NAICS 112 ("Animal production and aquaculture"), and NAICS 323 ("Printing and related support activity"). In the second row, we report the results obtained from industries in the retail sector: NAICS 448 ("Clothing stores"), NAICS 451 ("Sport, book and music stores"), and NAICS 452 ("General merchandise stores"). Finally, in the third row of Figure 4, we can also see how transportation and accommodation are negatively affected by a disaster shock: NAICS 487 ("Scenic and Sightseeing transportation"), NAICS 721 ("Accommodation"), and NAICS 722 ("Food services"). In the Online Appendix we report the response of wages for these industries. As for the case of the strengthened industries, wages move much less. Notable exceptions are the industries NAICS 323 ("Printing and related support activity") and NAICS 487 ("Scenic and Sightseeing transportation"), where the decline in wages is statistically significant.

Finally, Figure 5 reports a third group of industries, which we call "neutral", where the employment does not seem to react in a significant way to the disaster shock. Most of this group is made up of the largest industries in the Puerto Rican manufacturing sector: NAICS 325 ("Chemical manufacturing"), NAICS 311 ("Food manufacturing"), and NAICS 315 ("Apparel manufacturing"). In the Online Appendix, we show that for these industries the dynamics of wages also does not seem to be affected by disaster shocks.

Robustness. In the Online Appendix we experiment with the use of different measures of exposure to natural disasters. First, we increase the threshold from 33 to 64 knots in equation (1). Second, we use a different way of computing the wind speed, based on the classic formula of Deppermann (1947). Lastly, we substitute the population-weighted centroid with the geographical centroid of each county when computing the maximum windspeed affecting county $c$ during hurricane $H$. In all of the cases we consider, the results shown in Figures 2-5 are found to be very robust. 


\section{Figure 4: Employment Effects of Natural Disasters: Weakened Industries}
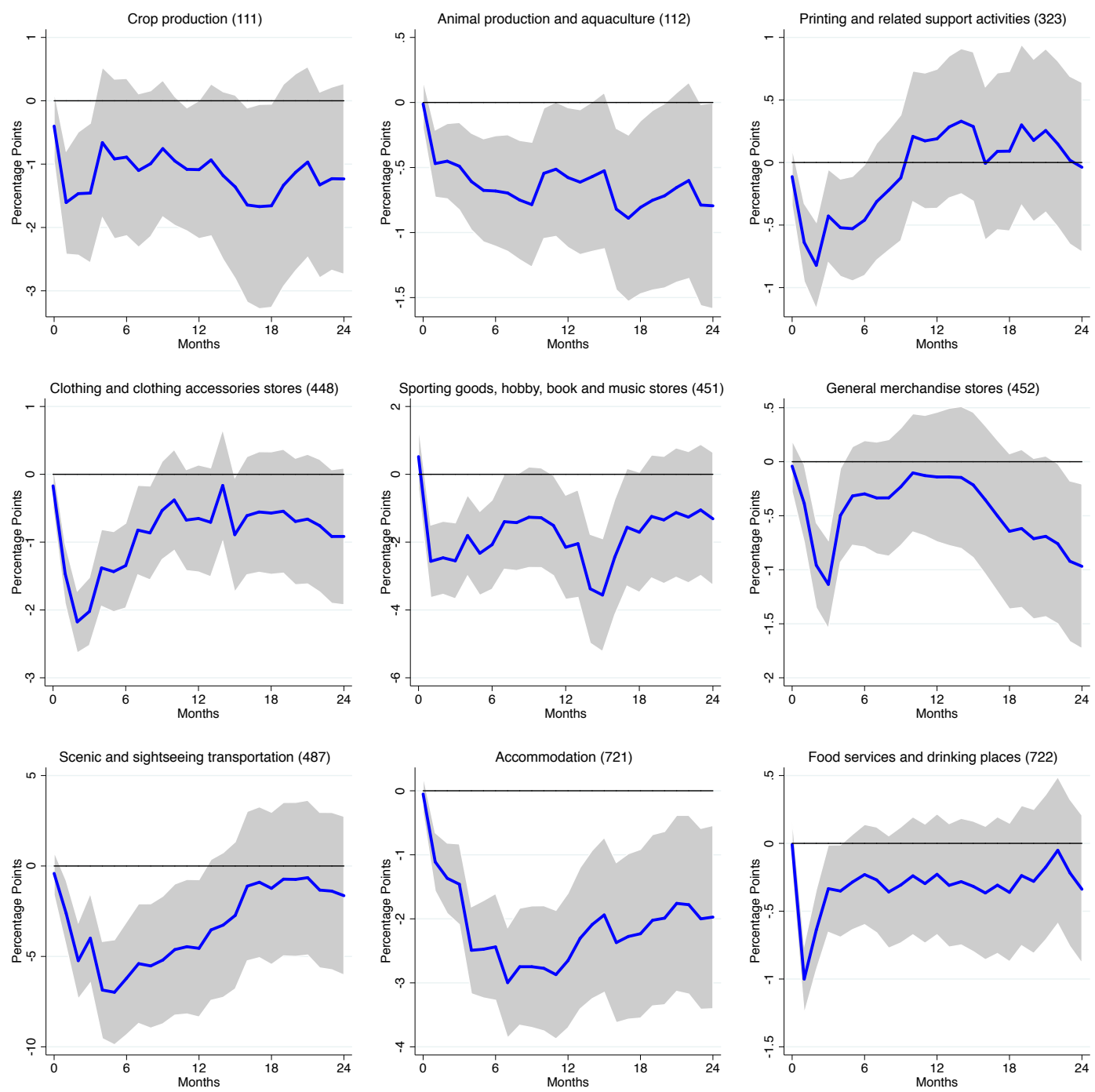

Discussion. Our first main result is consistent with the notion that natural disasters operate as temporary negative shocks to labor demand. Employment and wages fall temporarily, even when controlling for the evolution of the population. As for our second result, some of the heterogeneity we found across industries appears very sensible and self-evident: a disaster shock generates a construction boom and negatively affects retail, transport and accommodation industries. ${ }^{9}$ Some other results instead reveal a mechanism of transmission of natural disaster shocks to employment at detailed industry level: input-output linkages. The construction boom, for instance, is the likely trigger of the increase in employment in

${ }^{9}$ Our results on the construction sector are consistent with the findings by Strobl \& Walsh (2009). 


\section{Figure 5: Employment Effects of Natural Disasters: Neutral Industries}
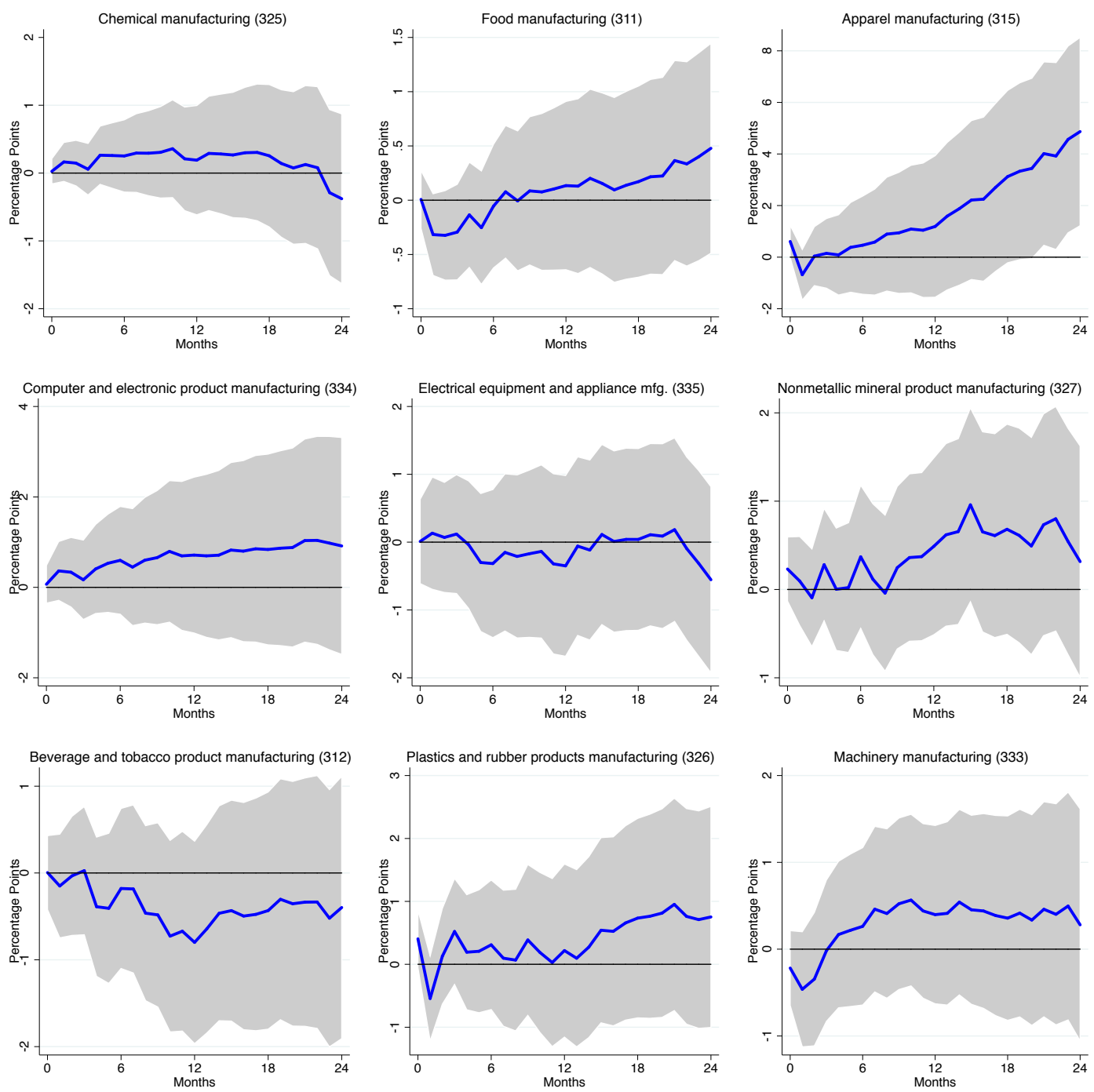

some of its important suppliers, such as the manufacturing of metals and of furnitures. To corroborate this hypothesis, we note that according to the 2019 BEA Input-Output table for the US, construction sectors are by far the most important buyers of both furniture manufacturing (absorbing 52\% of total sales) and fabricated metal product manufacturing (absorbing 26\% of total sales). The same construction boom might also explain the increase in employment in furniture stores and garden supply stores, which materializes only after a few months. By the same token, the fall in employment in the printing and support activities, might be explained by the reduction of activity in the retail and accommodation sectors, 
which could be important buyers of these activities, especially in Puerto Rico. ${ }^{10}$ Finally, the lack of impact of hurricanes on the employment of the largest manufacturing sectors (which might at first appear surprising) is consistent with what Pelli et al. (2020) find using firm level data for India, where cyclones appear to have a large impact on manufacturing firms' capital, but no significant effects on employment.

\section{Conclusion}

In this paper we study the short-run, dynamic employment effects of natural disasters. Using monthly data for over 90 3-digits NAICS industries and 78 Puerto Rican counties over the period 1995-2017, we show how the employment effects of natural disasters are consistent with temporary negative shocks to labor demand. Employment and wages fall temporarily, even when controlling for the evolution of the population. We also find an interesting heterogeneity at the industry level, which can be partly explained by input-output linkages. While we believe that the external validity of our quantitative results can be questionable, due to the relatively small scale of our laboratory, we are convinced that the key qualitative insights we provide are valid also for other contexts, such as developing countries, where data limitations hinder the type of analysis performed in this paper.

In particular, the fact that some industries contract and some others expand following natural disasters, suggests a new concept of resilience to natural disaster shocks: adaptabilitydriven employment resilience, defined as the potential ability of workers to temporarily reallocate from the contracting industries (i.e. accommodation) to the expanding ones (i.e. construction) in the aftermath of a natural disaster. The importance of these potential reallocations (or lack thereof) is witnessed by Sathyendrakajan et al. (2012), who surveyed construction firms in Sri Lanka. The lack of skilled workers was cited as the most important challenge faced by these firms during the post-disasters reconstruction efforts.

The IMF (2019) proposed a three-pillar "disaster resilience strategy", based on structural, financial, and post-disaster (and social) resilience. Adaptability-driven employment resilience could be an important building block of the post-disaster (and social) resilience. It could be achieved (or enhanced) by introducing new and different vocational training programs, aimed at endowing workers with a set of heterogeneous skills needed for rapid and temporary reallocations across different industries. As explained by the OECD (2010): "Vocational Education and Training (VET), can play a central role in preparing young people for work, developing skills of adults, and responding to the labour market needs of the economy".

\footnotetext{
${ }^{10}$ When looking at the overall US Input-Output table, our weakened service industries accounts for about $10 \%$ of sales of the sector NAICS 323 ("Printing and related support activity").
} 


\section{References}

Auerbach, A. J. \& Gorodnichenko, Y. (2013). Output Spillovers from Fiscal Policy. American Economic Review, 103, 141-146.

Barattieri, A. \& Cacciatore, M. (2020). Self-Harming Trade Policy? Protectionism and Production Networks. Working Paper 27630, NBER.

Belasen, A. \& Polachek, S. (2008). How Hurricanes Affect Wages and Employment in Local Labor Markets. American Economic Review, 98(2), 49-53.

Bernabe, A., Diop, B., Pelli, M., \& Tschopp, J. (2021). The Long-Term Effects of Unexpected Interruptions in Compulsory Schooling. mimeo.

Bertinelli, L. \& Strobl, E. (2013). Quantifying the Local Economic Growth Impact of Hurricane Strikes: An Analysis from Outer Space for the Caribbean. Journal of Applied Meteorology and Climatology, 52(8), 1688-1697.

Boose, E., Chamberlin, K., \& Foster, D. (2001). Landscape and Regional Impacts of Hurricanes in New England. Ecological Monographs, 71, 27-48.

Boose, E., Foster, D., \& Fluet, M. (1994). Hurricane Impacts to Tropical and Temperate Landscapes. Ecological Monographs, 64, 369-400.

Boose, E., Serrano, M., \& Foster, D. (2004). Landscape and Regional Impacts of Hurricanes in Puerto Rico. Ecological Monographs, 74(2), 335-352.

Boustan, L., Kahn, M., Rhode, P., \& Yanguas, M. (2020). The Effect of Natural Disasters on Economic Activity in US Counties: A Century of Data. Journal of Urban Economics, 118, 103257.

Cavallo, E., Galiani, S., Noy, I., \& Pantano, J. (2013). Catastrophic Natural Disasters and Economic Growth. The Review of Economics and Statistics, 95(5), 1549-1561.

Deppermann, C. (1947). Notes on the Origin and Structure of Philippine Typhoons. Bulletin of the American Meteorological Society, 28(9), 399-404.

Deryugina, T., Kawano, L., \& Levitt, S. (2018). The Economic Impact of Hurricane Katrina on Its Victims: Evidence from Individual Tax Returns. American Economic Journal: Applied Economics, 10(2), 202-233.

Elliott, R., Liu, Y., Strobl, E., \& Tong, M. (2019). Estimating the Direct and Indirect Impact of Typhoons on Plant Performance: Evidence from Chinese Manufacturers. Journal of Environmental Economics and Management, 98, 102252.

Emanuel, K. (2005). Increasing Destructiveness of Tropical Cyclones over the Past 30 Years. Nature, 436(7051), 686-688.

Felbermayr, G. \& Gröschl, J. (2014). Naturally Negative: The Growth Effects of Natural Disasters. Journal of Development Economics, 111, 92-106. 
Gallagher, J. \& Hartley, D. (2017). Household Finance after a Natural Disaster: The Case of Hurricane Katrina. American Economic Journal: Economic Policy, 9(3), 199-228.

Groen, J., Kutzbach, M., \& Polivka, A. (2020). Storms and Jobs: The Effect of Hurricanes on Individuals' Employment and Earnings over the Long Term. Journal of Labor Economics, $38(3)$.

Groen, J. \& Polivka, A. (2008). The Effect of Hurricane Katrina on the Labor Market Outcomes of Evacuees. American Economic Review Papers and Proceedings, 98(2), 43-48.

Holland, G. (1980). An Analytical Model of the Wind and Pressure Profiles in Hurricanes. Monthly Weather Review, 108, 1212-1218.

Hsiang, S. \& Jina, A. (2014). The Causal Effect of Environmental Catastrophe on Long-Run Economic Growth: Evidence from 6,700 Cyclones. Working Paper 20352, NBER.

IMF (2019). Building Resilience in Developing Countries Vulnerable to Large Natural Disasters. IMF Policy Paper 19/020, International Monetary Fund.

Jorda, O. (2005). Estimation and Inference of Impulse Responses by Local Projections. American Economic Review, 95, 161-182.

Jorda, O. \& Taylor, A. (2016). The Time for Austerity: Estimating the Average Treatment Effect of Fiscal Policy. Economic Journal, 126, 219-255.

Kirchberger, M. (2017). Natural Disasters and Labor Markets. Journal of Development Economics, 125, 40-58.

Leduc, S. \& Wilson, D. (2013). Roads to Prosperity or Bridges to Nowhere? Theory and Evidence on the Impact of Public Infrastructure Investment. NBER Macroeconomics Annual, 27, 89-142.

Lugo, A. (2019). Social-Ecological-Technological Effects of Hurricane Maria on Puerto Rico. Planning for Resilience under Extreme Events. Springer.

McIntosh, M. (2008). Measuring the Labor Market Impacts of Hurricane Katrina Migration: Evidence from Houston, Texas. American Economic Review, 98(2), 54-57.

OECD (2010). Learning for Jobs - OECD Reviews of Vocational Education and Training. OECD.

Ortega, F. \& Taspinar, S. (2018). Rising Sea Levels and Sinking Property Values: Hurricane Sandy and New YorkâĂŹs Housing Market. Journal of Urban Economics, 106(C), 81-100.

Ottonello, P. \& Winberry, T. (2020). Financial Heterogeneity and the Investment Channel of Monetary Policy. Econometrica, 88, 2473-2502.

Pelli, M. \& Tschopp, J. (2017). Comparative Advantage, Capital Destruction, and Hurricanes. Journal of International Economics, 108, 315-337. 
Pelli, M., Tschopp, J., Bezmaternykh, N., \& Eklou, K. (2020). In the Eye of the Storm: Firms and Capital Destruction in India. IMF Working Papers 2020/203, International Monetary Fund.

Peri, G., Rury, D., \& Wiltshire, J. (2020). The Economic Impact of Migrants from Hurricane Maria. Working Paper 27718, NBER.

Sacerdote, B. (2012). When the Saints Go Marching Out: Long-Term Outcomes for Student Evacuees from Hurricanes Katrina and Rita. American Economic Journal: Applied Economics, 4(1), 109-35.

Sathyendrakajan, N., Karunasena, G., \& Wedikkara, C. (2012). Exploring Capacity of Construction Industry Post Disaster Housing Reconstruction. Built-Environment Sri Lanka, $11(1), 2-6$.

Seetharam, I. (2018). The Indirect Effects of Hurricanes: Evidence from Firm Internal Networks. mimeo.

Strobl, E. (2011). The Economic Growth Impact of Hurricanes: Evidence from U.S. Coastal Counties. The Review of Economics and Statistics, 93(2), 575-589.

Strobl, E. \& Walsh, F. (2009). The Rebuilding Effects of Hurricanes: Evidence from Employment in the US Construction Industry. Economics bullettin, 29(4), 3059-3066.

Vu, T. B. \& Noy, I. (2018). Natural Disasters and Firms in Vietnam. Pacific Economic Review, 23(3), 426-452.

Watkins, D., Torres Zayas, H., Velez Vega, C., Rosario, Z., Welton, R., Agosto Arroyo, L., Zulmarie, N., Reguero, J., Santos Rivera, A., Huerta-Montanez, G., Brown, P., Alshawabkeh, A., Cordero, J., \& Meeker, J. (2020). Investigating the Impact of Hurricane Maria on an Ongoing Birth Cohort in Puerto Rico. Population and Environment, 42, 95-111.

Yang, D. (2008). Coping with Disaster: The Impact of Hurricanes on International Financial Flows, 1970-2002. The B.E. Journal of Economic Analysis and Policy, 8(2). 


\section{A Appendix}

\section{A.1 HURRECON model}

The HURRECON model (see Boose et al., 1994, 2001, 2004) describes sustained wind velocity at any point within a cyclone's vortex using information on the track, size, intensity, and cover type (land or water) of a hurricane. In the case of this paper, we use this model to compute sustained wind velocity at each population-weighted county centroid: ${ }^{11}$

$$
w_{c h}=F\left[V_{h}-S(1-\sin T) \frac{V_{f}}{2}\right]\left[\left(\frac{R_{m}{ }^{B}}{R} e^{1-\left[\frac{R_{m}}{R}\right]^{B}}\right)\right]^{1 / 2}
$$

where $F$ is a scaling parameter for the effect of friction set at 0.8 , since all the point of interest to us are situated on land (this parameter is usually set equal to 1 for points over water and to 0.8 for points over land); $V_{h}$ is the wind velocity at the eye at landmark $h$, which we linearly interpolate from the best track data; $S$ is a scaling parameter for the asymmetry due to the forward motion of the storm, set to 1 (i.e. peak wind speed on the right side minus peak wind speed on the left side equals the forward velocity of the hurricane $-V_{f}$, as defined in Boose et al., 2001); $T$ is the clockwise angle between the forward path of the hurricane and a radial line connecting the eye of the hurricane to the population-weighted centroid of a county; $V_{f}$ is the forward velocity of the hurricane, i.e. the speed at which the hurricane is moving forward; $R_{m}$ is the radius of maximum winds, obtained from the best track data; $R$ is the radial (or Euclidean) distance from the center of the hurricane to the population-weighted centroid of a county; and $B$ is a scaling parameter controlling for the shape of the wind profile curve (usually included between 1.2 and 1.5, and set at 1.35).

The parameters of this equation, adapted from Holland's equation for the cyclostrophic wind (Holland, 1980), have been set following Boose et al. (2004) that parameterized and validated the model for Puerto Rico.

\footnotetext{
${ }^{11}$ Velocity and wind direction are measured relative to the surface of the Earth, and angles are measured in degrees.
} 


\title{
The Short-Run, Dynamic Employment Effects of Natural Disasters: New Insights ONLINE APPENDIX
}

\author{
June 2021
}

This appendix contains some supplementary material not inserted (due to space constraints) in the main text of Barattieri, Borda, Brugnoli, Pelli and Tschopp (2021). 


\section{A Hurricanes used for the baseline specification}

In this Section, we report the names of the 23 hurricanes and storms we use in our baseline specification, together with the year and month when they hit Puerto Rico and the maximum category they reached according to the Simpson and Riehl scale.

Table A.1: Hurricanes

\begin{tabular}{lcrr}
\hline Name & Year & Month & Category \\
\hline Luis & 1995 & 9 & 4 \\
Marilyn & 1995 & 9 & 4 \\
Bertha & 1996 & 7 & $2-3$ \\
Hortense & 1996 & 9 & 4 \\
George & 1998 & 9 & 3 \\
José & 1999 & 10 & $\mathrm{TS}$ \\
Lenny & 1999 & 11 & 4 \\
Debby & 2000 & 8 & 1 \\
Keith & 2000 & 10 & 3 \\
Dean & 2001 & 8 & 1 \\
Jeanne & 2004 & 9 & 3 \\
Frances & 2004 & 9 & 4 \\
Dean & 2007 & 5 & 5 \\
Olga & 2007 & 12 & $\mathrm{TS}$ \\
Omar & 2008 & 10 & 4 \\
Earl & 2010 & 8 & 4 \\
Irene & 2011 & 8 & 3 \\
Karen & 2013 & 10 & $\mathrm{TS}$ \\
Gonzalo & 2014 & 10 & 4 \\
Danny & 2015 & 8 & 3 \\
Erika & 2015 & 8 & 5 \\
Irma & 2017 & 9 & 5 \\
Maria & 2017 & 9 &
\end{tabular}

Note: Category refers to the category corresponding to the maximum windspeed reached by the hurricane according to the SaffirSimpson wind scale. TS stands for tropical storm. 


\section{B Puerto Rico}

In this Section, we report the structure of Puerto Rico private employment using NAICS 2-digits industries (Table B.1.1) and the structure of Puerto Rican private manufacturing employment using NAICS 3-digits industries (Table B.1.2). We present average figures across our sample period. In Figures B.1.1 and B.1.2 we report instead the dynamics over time of employment in selected industries. Finally, in Table B.2.1 and Figure B.2.1 we show the total population according to the 2010 Census data for the 35 most populous counties in Puerto Rico and the percentage change of population in each county over the period 2010-2017.

\section{B.1 Puerto Rico Private Employment}

\section{Table B.1.1: Private Employment Structure}

\begin{tabular}{|c|c|c|c|}
\hline$\overline{\text { NAICS2 }}$ & Sector Name & Av. Employment (count) & Empl. Share \\
\hline$\overline{11}$ & Agriculture, forestry, fishing and hunting & 12,560 & $1.86 \%$ \\
\hline 21 & Mining, quarrying, and oil and gas extraction & 1000 & $0.15 \%$ \\
\hline 22 & Utilities & 240 & $0.04 \%$ \\
\hline 23 & Construction & 48,130 & $7.13 \%$ \\
\hline 30 & Manufacturing & 116,020 & $17.20 \%$ \\
\hline 42 & Wholesale trade & 30,420 & $4.51 \%$ \\
\hline $44-45$ & Retail trade & 123,740 & $18.34 \%$ \\
\hline $48-49$ & Transportation and warehousing & 16.58 & $2.46 \%$ \\
\hline 51 & Information & 16,810 & $2.49 \%$ \\
\hline 52 & Finance and insurance & 29,570 & $4.38 \%$ \\
\hline 53 & Real estate and rental and leasing & 13,040 & $1.93 \%$ \\
\hline 54 & Professional and technical services & 24,880 & $3.69 \%$ \\
\hline 55 & Management of companies and enterprises & 12,230 & $1.81 \%$ \\
\hline 56 & Administrative and waste services & 59.11 & $8.76 \%$ \\
\hline 61 & Educational services & 23,900 & $3.54 \%$ \\
\hline 62 & Health care and social assistance & 65.83 & $9.76 \%$ \\
\hline 71 & Arts, entertainment, and recreation & 3,360 & $0.50 \%$ \\
\hline 72 & Accommodation and food services & 61.40 & $9.10 \%$ \\
\hline 81 & Other services, except public administration & 15,220 & $2.26 \%$ \\
\hline \multirow[t]{2}{*}{99} & Unclassified & 690 & $0.10 \%$ \\
\hline & TOTAL & 674,800 & $100.00 \%$ \\
\hline
\end{tabular}




\section{Table B.1.2: Manufacturing Employment Structure}

\begin{tabular}{llrr}
\hline NAICS3 & Industry Name & Av. Employment (count) & Empl. Share \\
\hline 325 & Chemical manufacturing & 25,360 & $21.9 \%$ \\
311 & Food manufacturing & 14,840 & $12.8 \%$ \\
315 & Apparel manufacturing & 14,820 & $12.8 \%$ \\
339 & Miscellaneous manufacturing & 12,280 & $10.6 \%$ \\
334 & Computer and electronic product manufacturing & 10,430 & $9.0 \%$ \\
335 & Electrical equipment and appliance mfg. & 6,700 & $5.8 \%$ \\
332 & Fabricated metal product manufacturing & 5,070 & $4.4 \%$ \\
327 & Nonmetallic mineral product manufacturing & 3,390 & $2.9 \%$ \\
312 & Beverage and tobacco product manufacturing & 3,250 & $2.8 \%$ \\
316 & Leather and allied product manufacturing & 3,020 & $2.6 \%$ \\
326 & Plastics and rubber products manufacturing & 2,930 & $2.5 \%$ \\
323 & Printing and related support activities & 2,320 & $2.0 \%$ \\
333 & Machinery manufacturing & 2,310 & $2.0 \%$ \\
337 & Furniture and related product manufacturing & 2,200 & $1.9 \%$ \\
336 & Transportation equipment manufacturing & 1,820 & $1.6 \%$ \\
322 & Paper manufacturing & 1,780 & $1.5 \%$ \\
324 & Petroleum and coal products manufacturing & 1,210 & $1.0 \%$ \\
314 & Textile product mills & 960 & $0.8 \%$ \\
331 & Primary metal manufacturing & 650 & $0.6 \%$ \\
321 & Wood product manufacturing & 420 & $0.4 \%$ \\
313 & Textile mills & 230 & $0.2 \%$ \\
\hline & TOTAL & 116,020 & $100.0 \%$ \\
\hline \hline
\end{tabular}


Figure B.1.1: Private Employment Dynamics (in thousands)



Figure B.1.2: Manufacturing Employment Dynamics (in thousands)

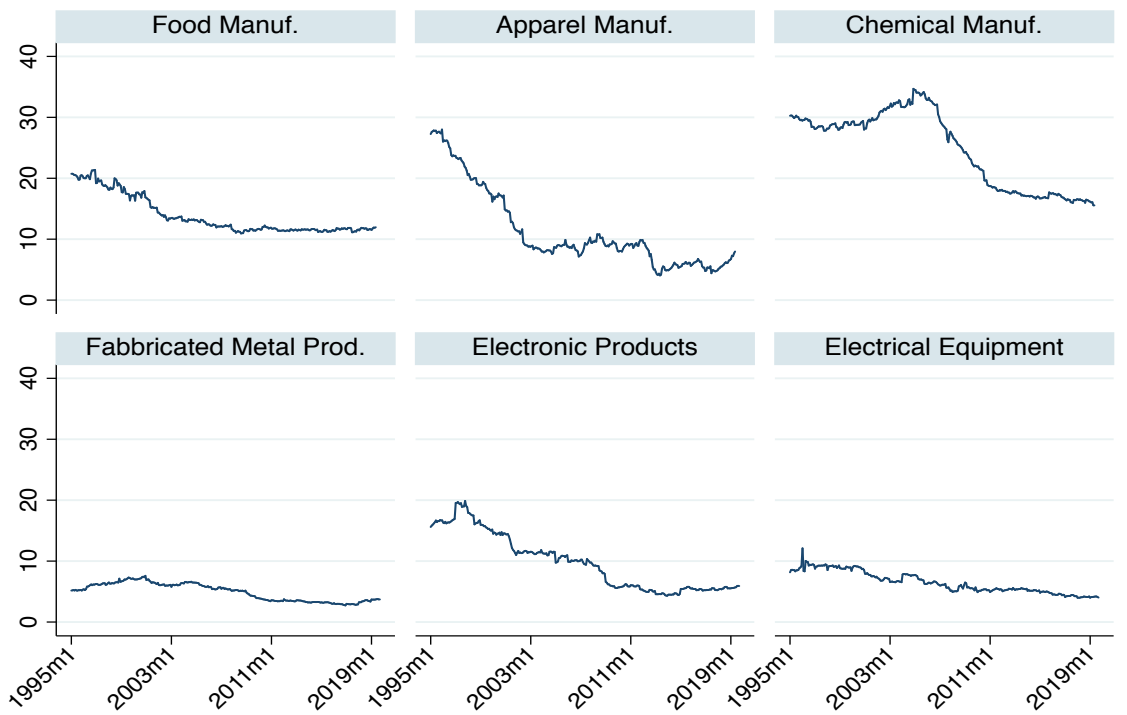




\section{B.2 Puerto Rico Population}

\section{Table B.2.1: Population Structure, Top-35 Counties}

\begin{tabular}{lrr}
\hline County Name & 2010 Population & Pop. Share \\
San Juan Municipio & 394,235 & $10.59 \%$ \\
Bayamun Municipio & 207,649 & $5.58 \%$ \\
Carolina Municipio & 176,425 & $4.74 \%$ \\
Ponce Municipio & 165,723 & $4.45 \%$ \\
Caguas Municipio & 142,863 & $3.84 \%$ \\
Guaynabo Municipio & 97,792 & $2.63 \%$ \\
Arecibo Municipio & 96,222 & $2.59 \%$ \\
Toa Baja Municipio & 89,467 & $2.40 \%$ \\
Mayagez Municipio & 88,793 & $2.39 \%$ \\
Trujillo Alto Municipio & 74,779 & $2.01 \%$ \\
Toa Alta Municipio & 74,282 & $2.00 \%$ \\
Aguadilla Municipio & 60,766 & $1.63 \%$ \\
Vega Baja Municipio & 59,548 & $1.60 \%$ \\
Humacao Municipio & 58,375 & $1.57 \%$ \\
Rio Grande Municipio & 54,295 & $1.46 \%$ \\
Cabo Rojo Municipio & 50,971 & $1.37 \%$ \\
Juana Diaz Municipio & 50,736 & $1.36 \%$ \\
Cayey Municipio & 48,111 & $1.29 \%$ \\
Canuvanas Municipio & 47,685 & $1.28 \%$ \\
Isabela Municipio & 45,654 & $1.23 \%$ \\
Gurabo Municipio & 45,561 & $1.22 \%$ \\
Guayama Municipio & 45,277 & $1.22 \%$ \\
Manati Municipio & 44,041 & $1.18 \%$ \\
Cidra Municipio & 43,483 & $1.17 \%$ \\
San Sebastian Municipio & 42,347 & $1.14 \%$ \\
Hatillo Municipio & 41,979 & $1.13 \%$ \\
Aguada Municipio & 41,913 & $1.13 \%$ \\
Yauco Municipio & 41,838 & $1.12 \%$ \\
San Lorenzo Municipio & 41,023 & $1.10 \%$ \\
Coamo Municipio & 40,576 & $1.09 \%$ \\
Juncos Municipio & 40,349 & $1.08 \%$ \\
Moca Municipio & 40,100 & $1.08 \%$ \\
Vega Alta Municipio & 39,946 & $1.07 \%$ \\
Las Piedras Municipio & 38,714 & $1.04 \%$ \\
Dorado Municipio & 38,239 & $1.03 \%$ \\
Yabucoa Municipio & 37,881 & $1.02 \%$ \\
Corozal Municipio & 37,130 & $1.00 \%$ \\
. & & \\
. & & $\mathbf{1 0 0 . 0 0 \%}$ \\
TOTAL & & \\
Tom & & \\
\hline
\end{tabular}

Figure B.2.1: Puerto Rico Population Change, 2010-2017

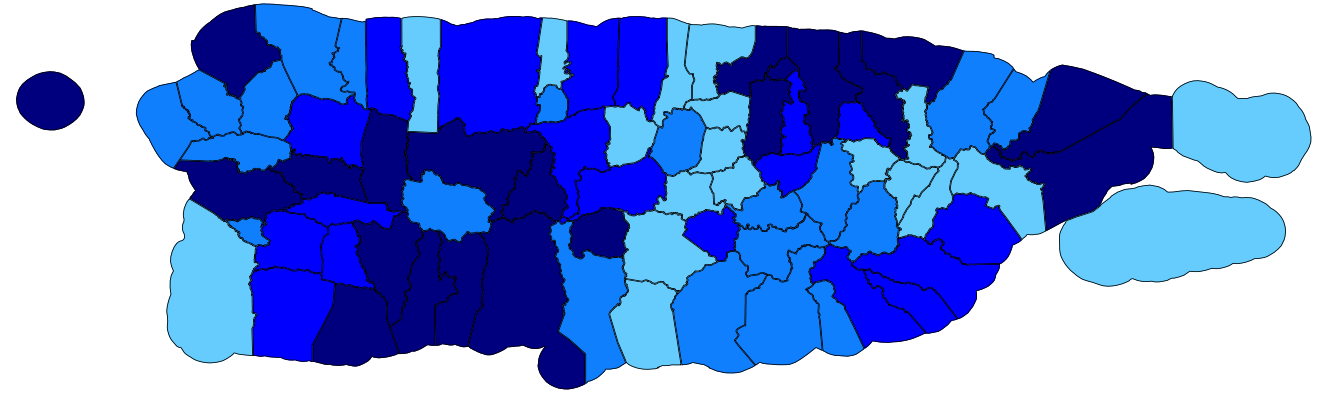




\section{Baseline Analysis: Wage Effects}

In Figures C.1, C.2, and C.3 we report the evolution of average weekly wages following a natural disaster. We plot the results obtained for the same industries whose employment responses are reported in Figures 3, 4 and 5 in the main text.

Figure C.1: Wage Effects of Natural Disasters: Strengthened Industries
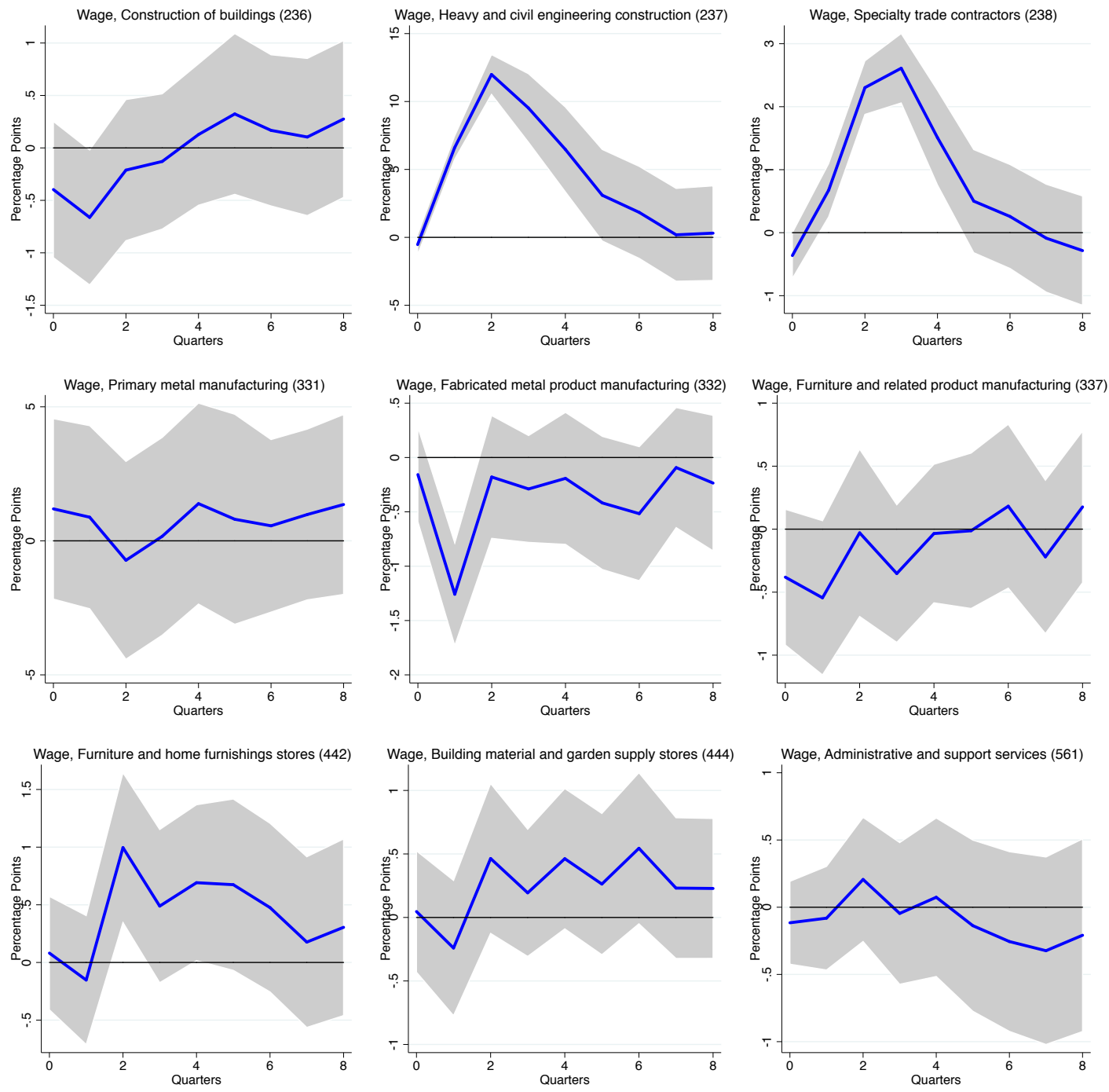
Figure C.2: Wage Effects of Natural Disasters: Weakened Industries
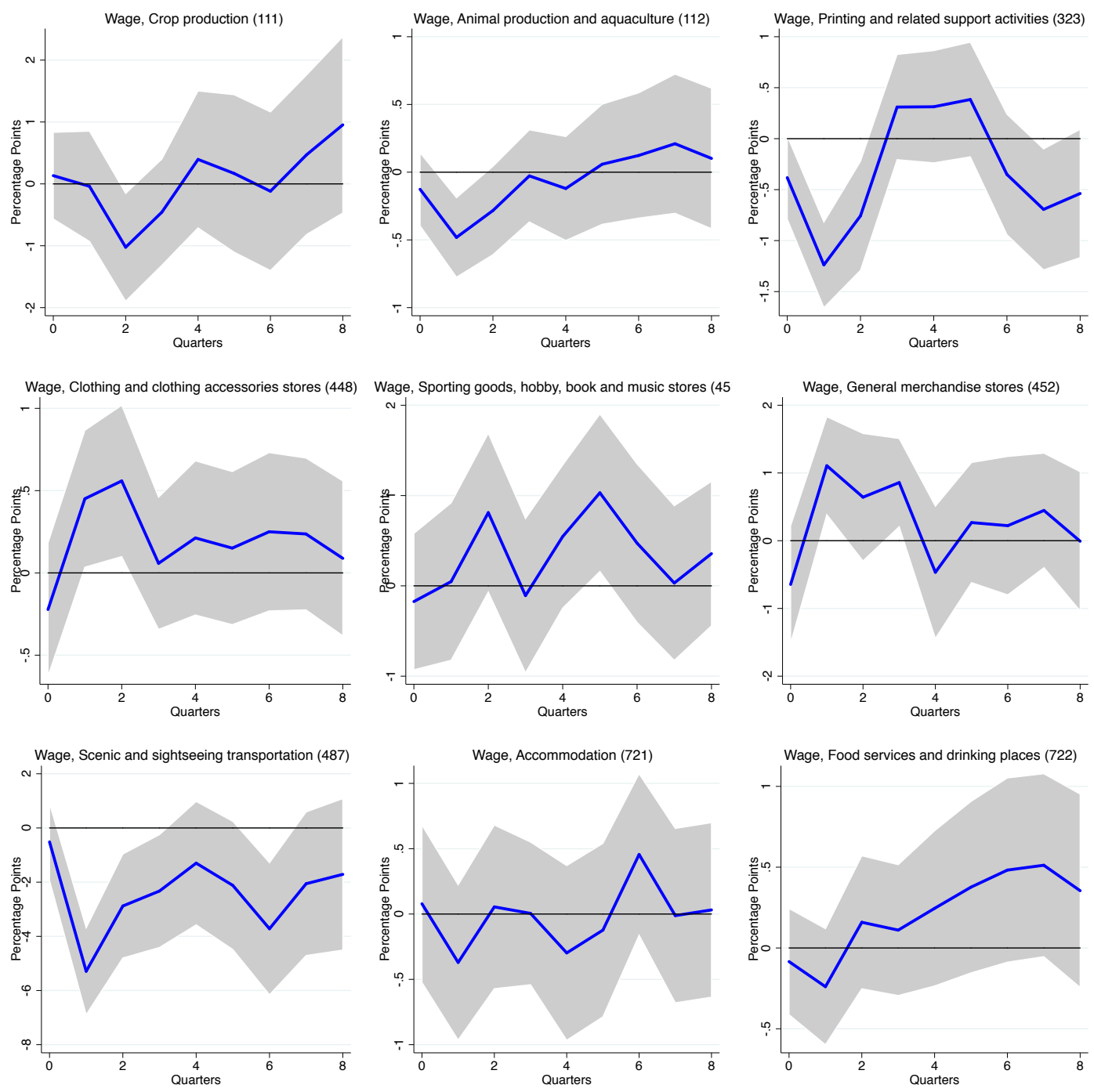
Figure C.3: Wage Effects of Natural Disasters: Neutral Industries
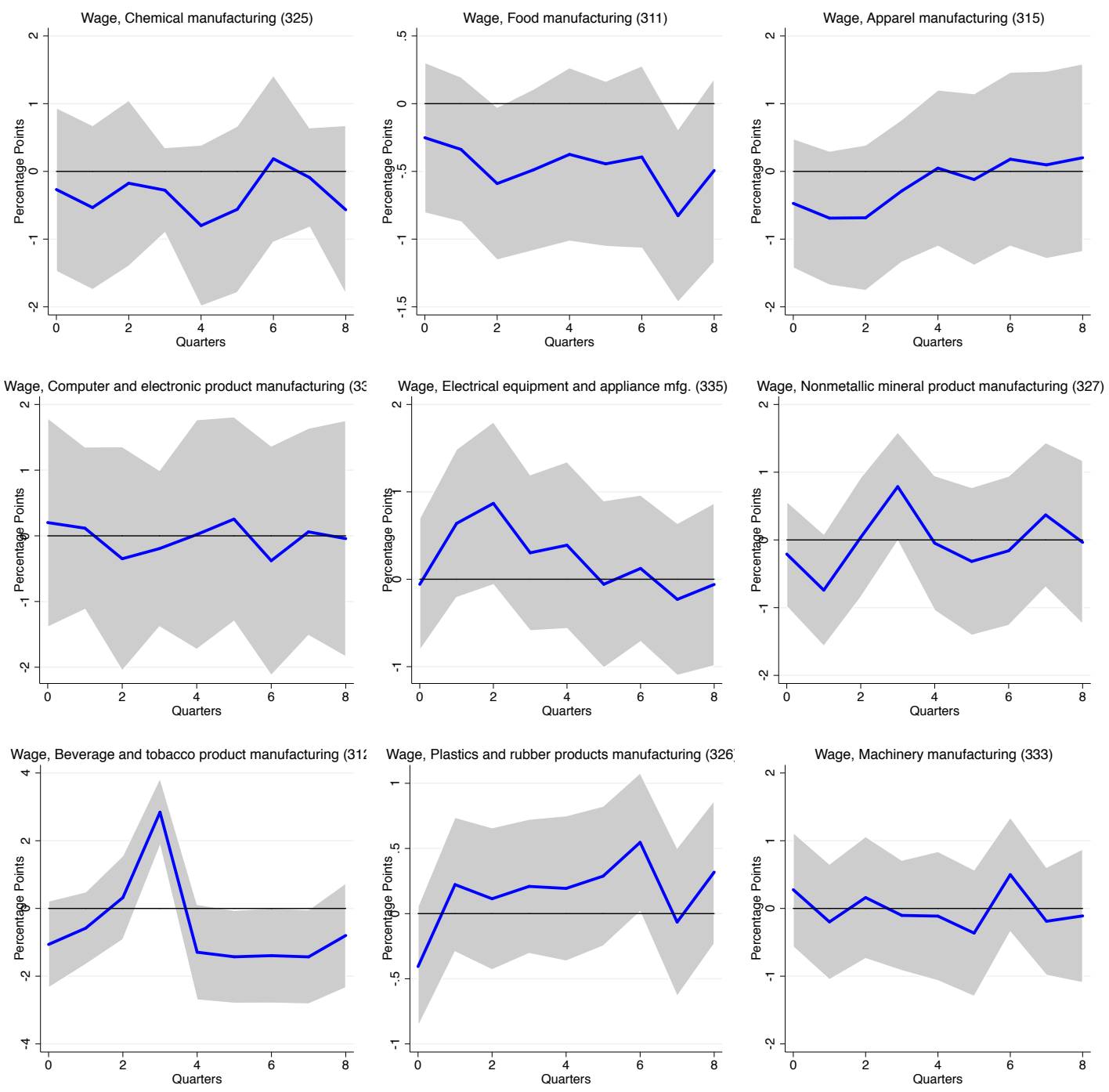


\section{Robustness I: 64 Knots Threshold}

Figures D.1, D.2, D.3, and D.4 report the equivalent of the analysis presented in the Figures 2-5 of the main text. Here we change the threshold used in equation 1 from 33 to 64 knots, which defines a category 1 hurricanes according to the Simpson and Riehl scale. The results are qualitatively similar to the one presented in the main paper.

\section{Figure D.1: Employment Effects of Natural Disasters: Panel Results}
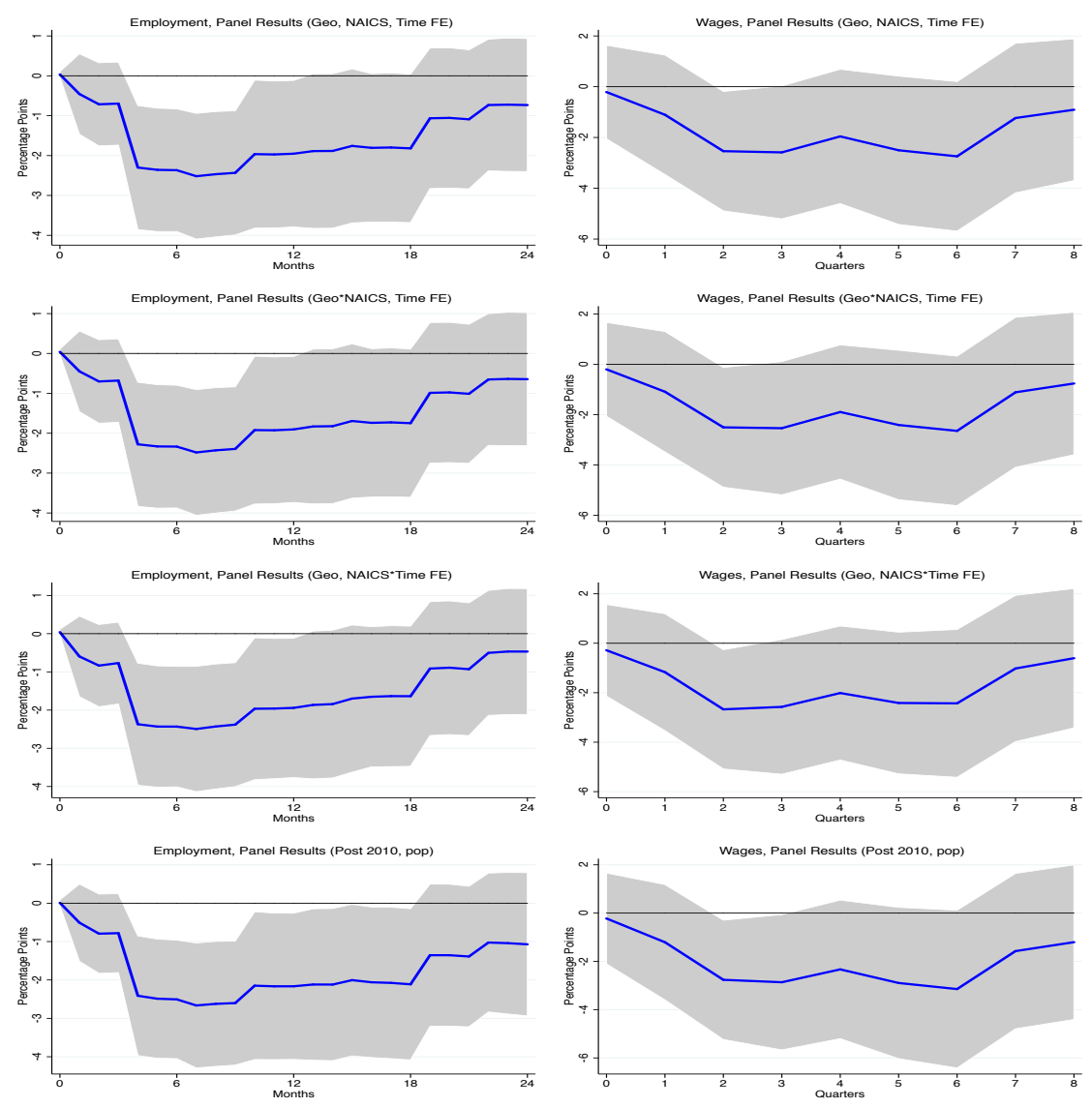
Figure D.2: Employment Effects of Natural Disasters: Strengthened Industries
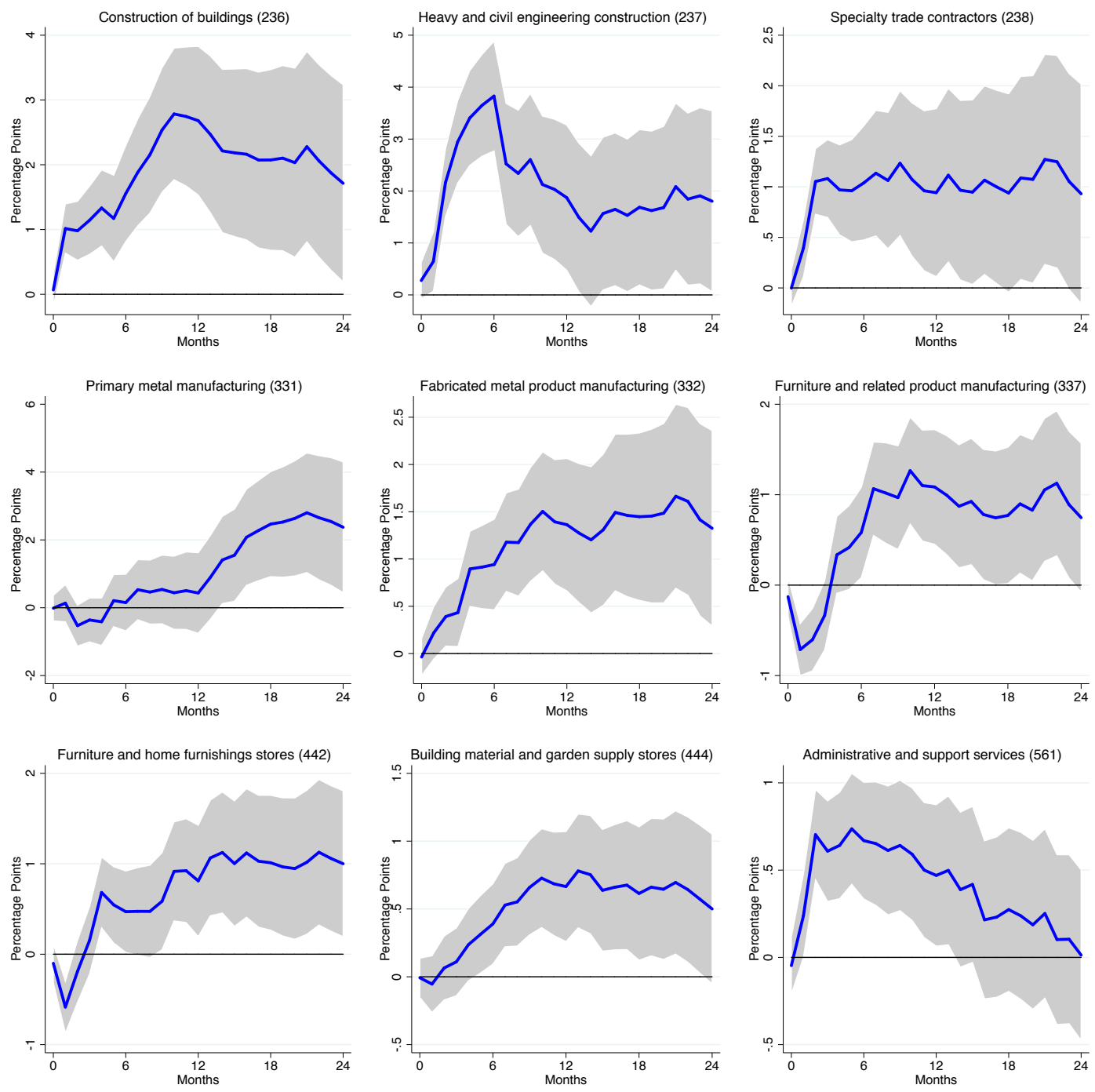
Figure D.3: Employment Effects of Natural Disasters: Weakened Industries
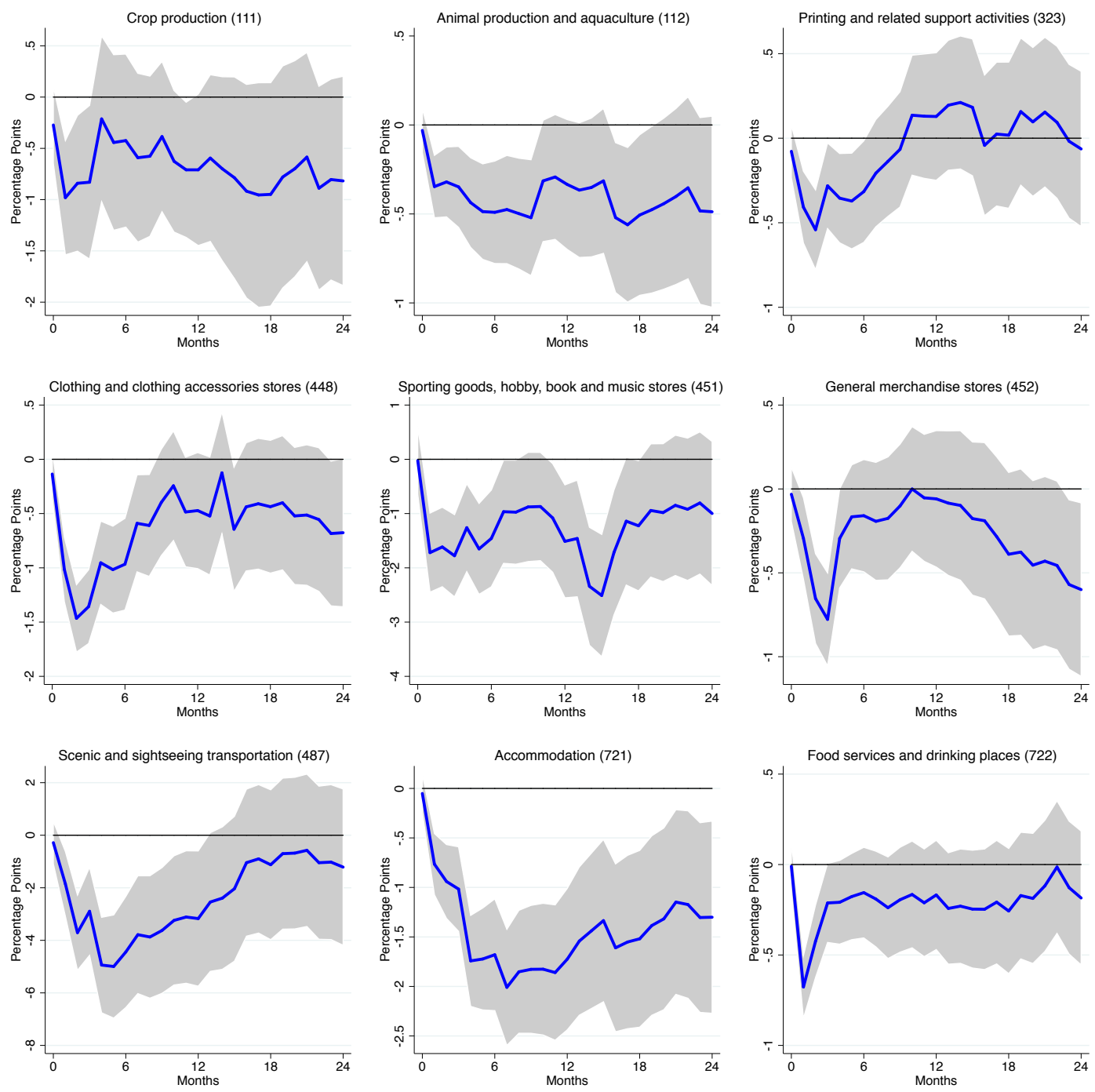
Figure D.4: Employment Effects of Natural Disasters: Neutral Industries
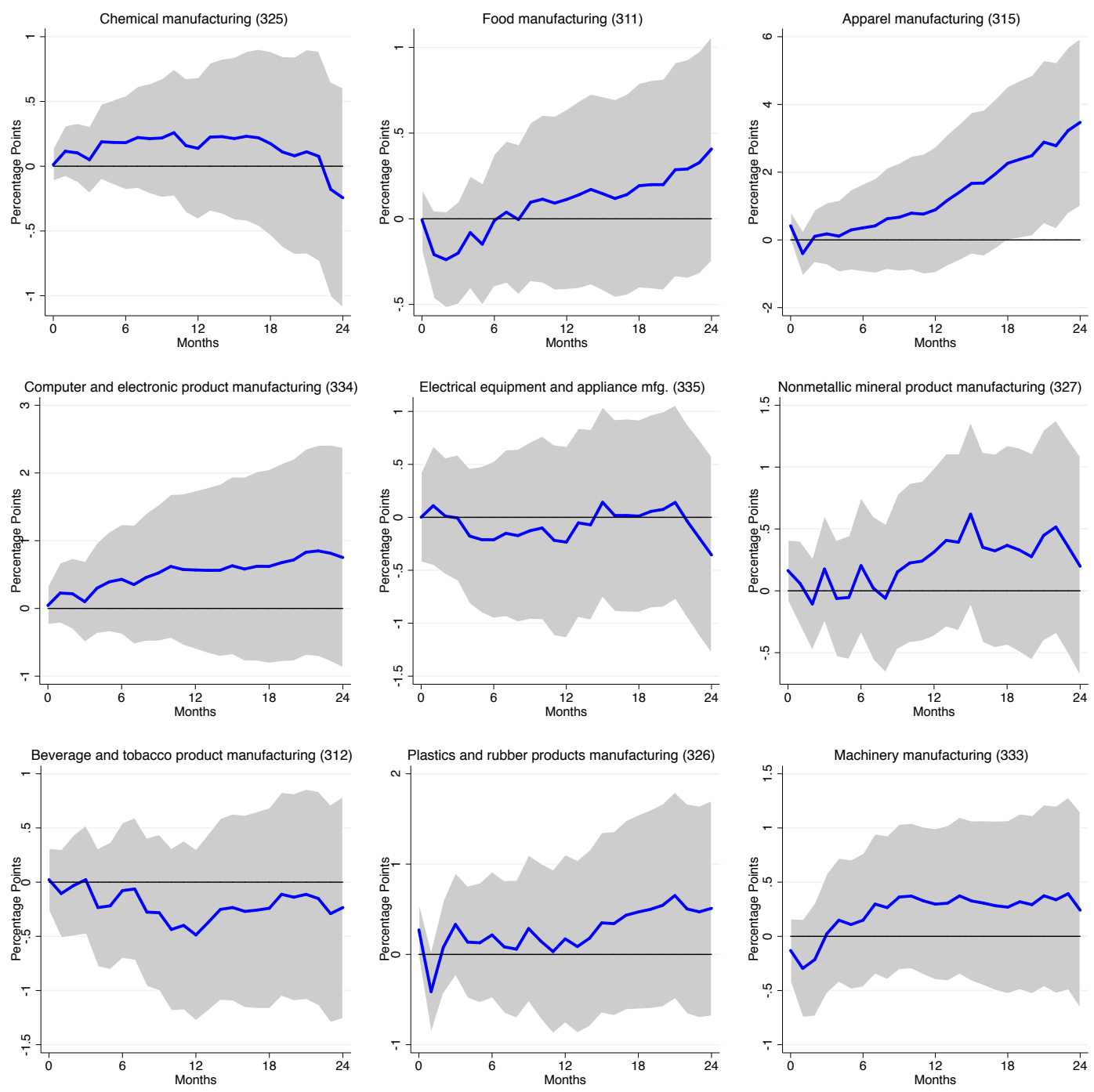


\section{E Robustness II: Depperman Formula}

Figures E.1, E.2, E.3, and E.4 report the equivalent of the analysis presented in the Figures 2-5 of the main text. Here we change the formula used to compute $w_{c h}$, the wind speed at each county $c$ for each landmark $h$. We use here the classical Depperman formula instead of the HURRECON model. The Depperman formula describes sustained wind velocity at any point, in the specific case each population weighted centroid, in the following way:

$$
w_{c h}=V_{h} \cdot\left(\frac{D_{c h}}{26.9978}\right) \text { if } D_{c h} \leq 26.9978 \quad w_{c h}=V_{h} \cdot\left(\frac{26.9978}{D_{c h}}\right)^{0.5} \text { if } D_{c h}>26.9978
$$

$D_{c h}$ is the radial distance of each county centroid from the landmark $h$ and $V_{h}$ the wind speed at the landmark $h$. The number $26.9978(50 \mathrm{~km})$ corresponds to Simpson and Riehl radius of maximum wind speed. In general, the radius of maximum wind speed is computed using the gap between the barometric pressure between the center and the outskirts of the storm. Given the high number of missing measures of barometric pressure in the data, we follow Simpson \& Riehl (1981) and Hsu \& Zhongde (1998) and use the average radius of maximum windspeed $(50 \mathrm{~km})$ for all cyclones. The results are very similar to those reported in the main text. 
Figure E.1: Employment Effects of Natural Disasters: Panel Results
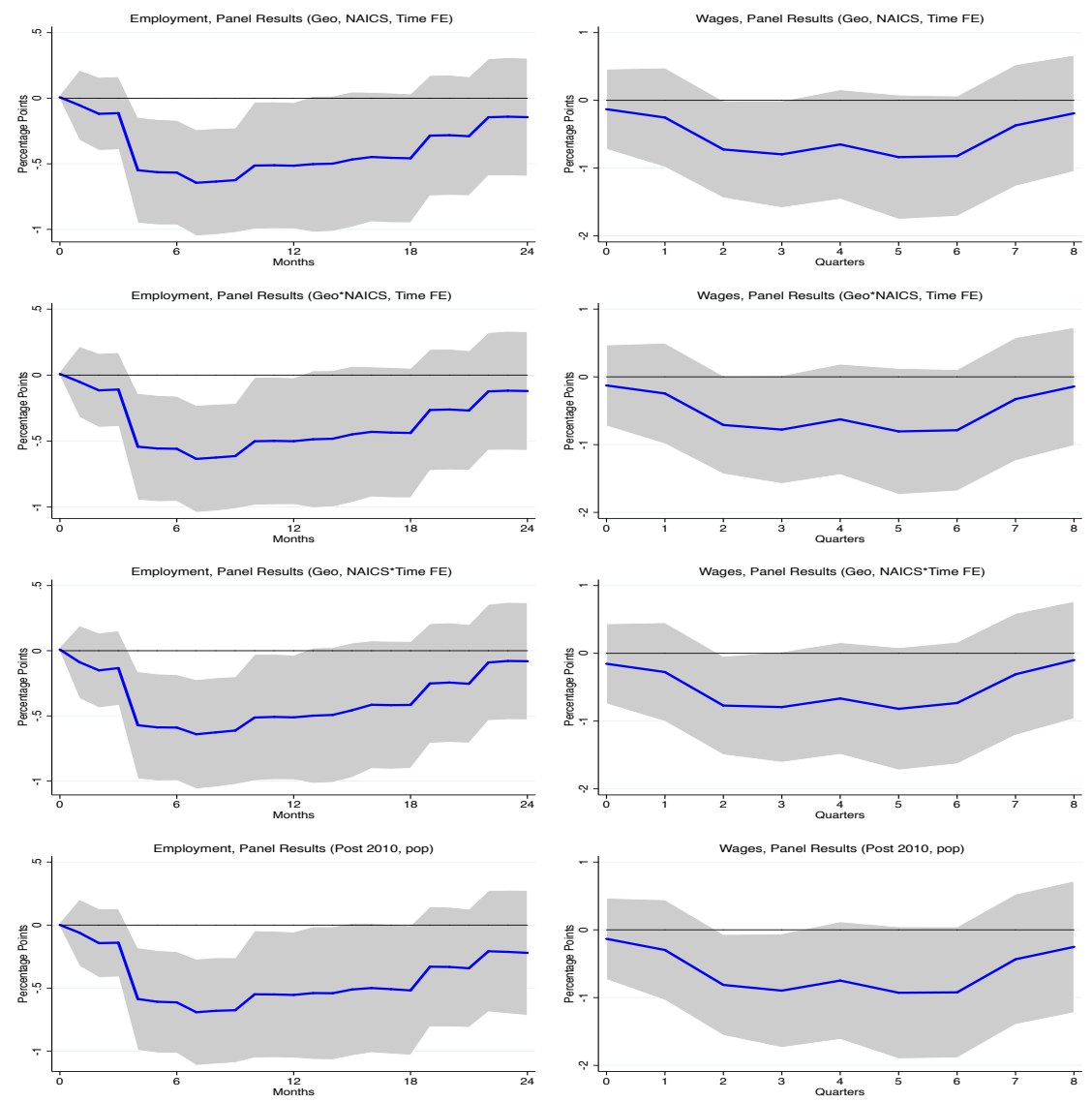
Figure E.2: Employment Effects of Natural Disasters: Strengthened Industries
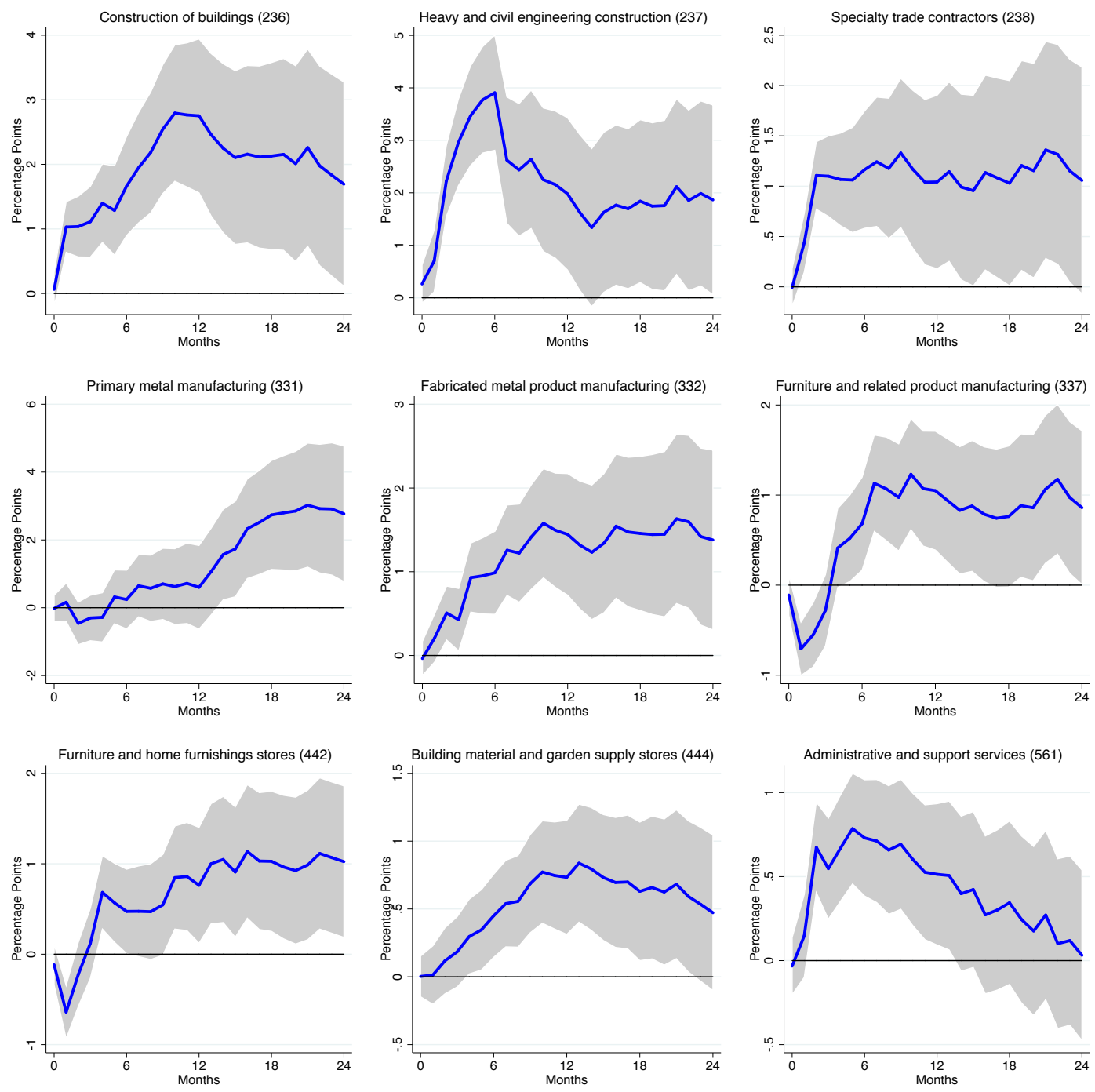
Figure E.3: Employment Effects of Natural Disasters: Weakened Industries
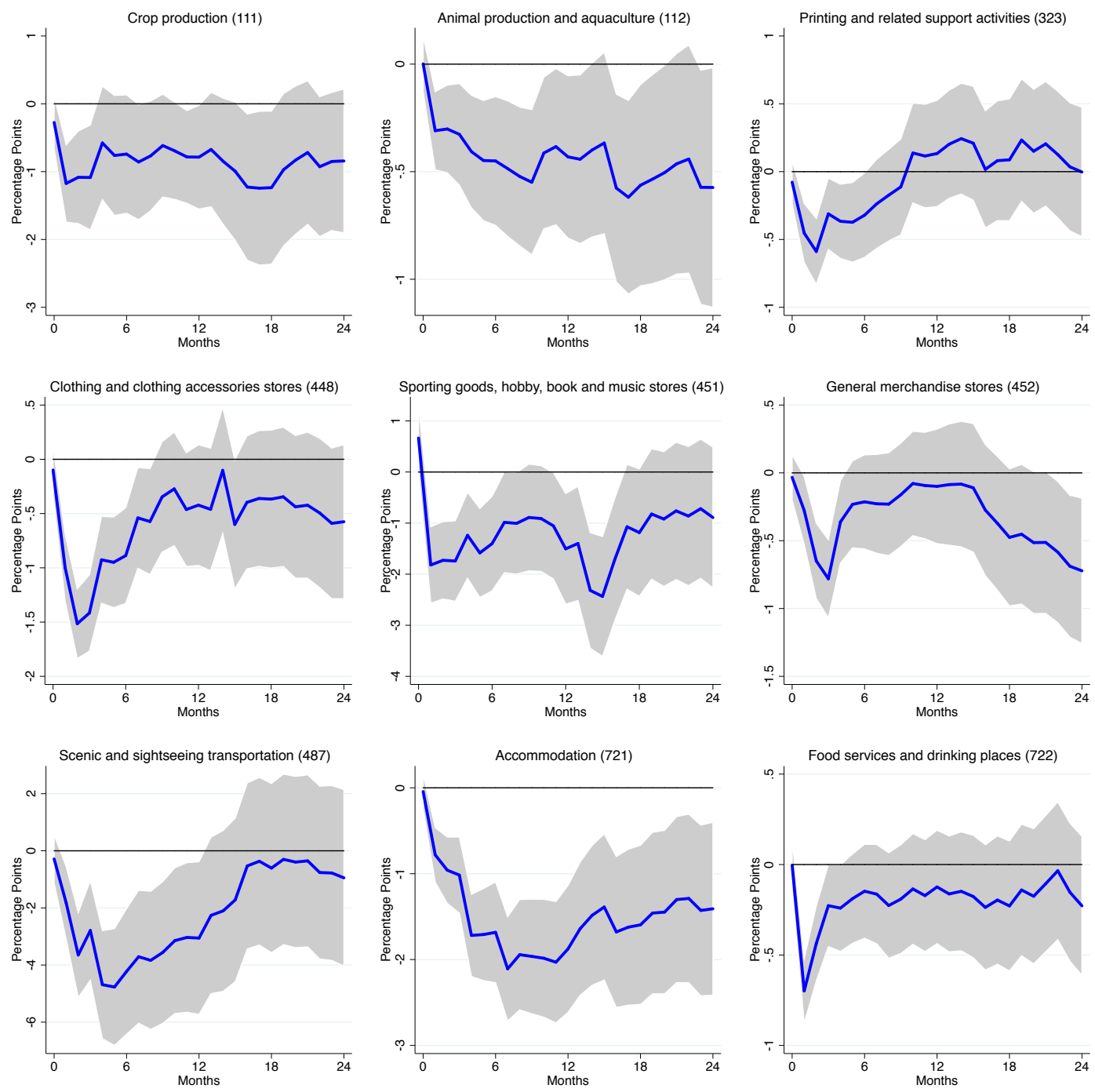
Figure E.4: Employment Effects of Natural Disasters: Neutral Industries
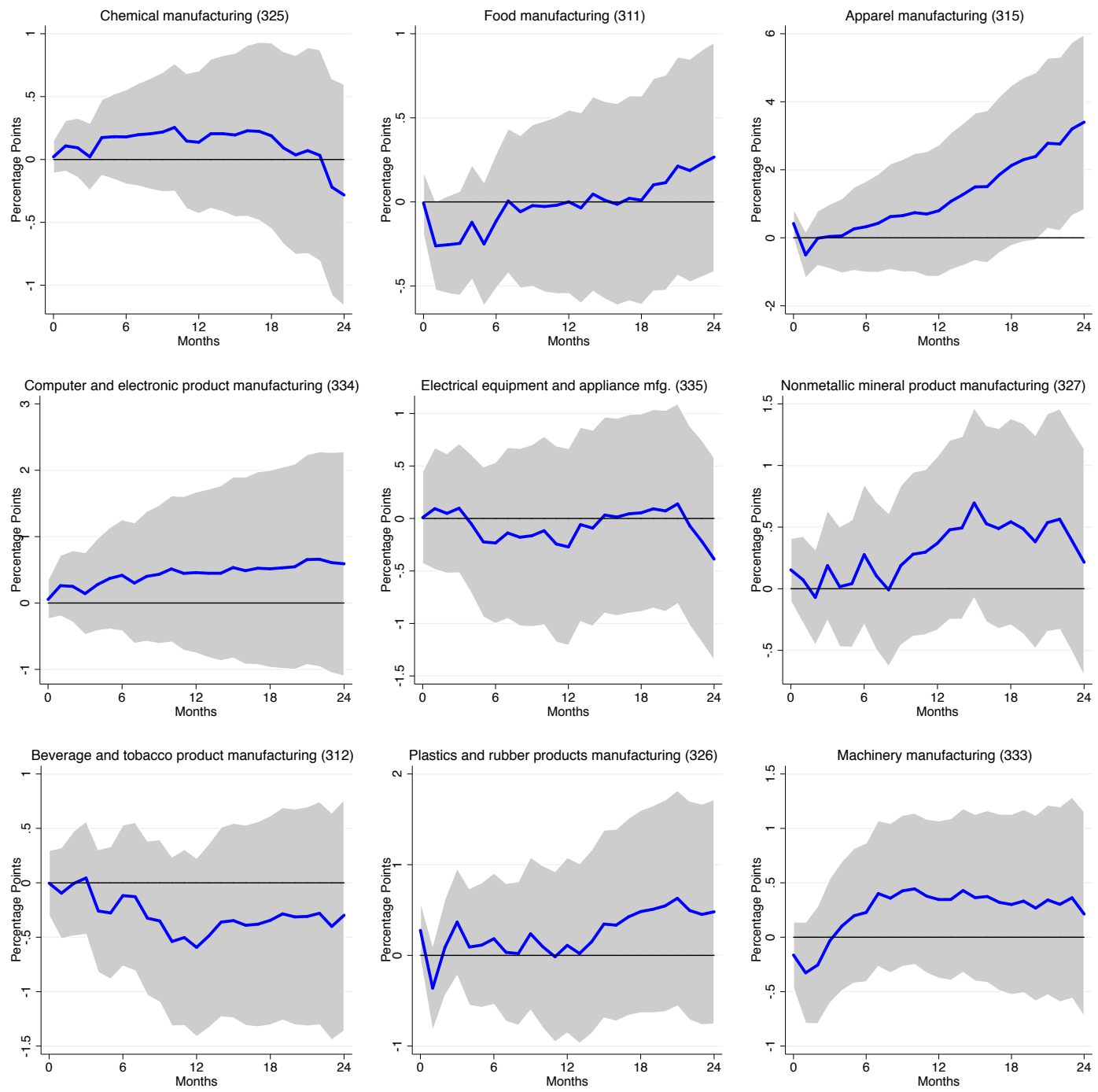


\section{F Robustness III: Geographical Centroids}

Figures F.1, F.2, F.3, and F.4 report the equivalent of the analysis presented in the Figures 2-5 of the main text. Here we change the definition of the centroid of a county. Instead of using population weighted centroids, we use simply geographical centroids. The results are very similar to those reported in the main text.

Figure F.1: Employment Effects of Natural Disasters: Panel Results
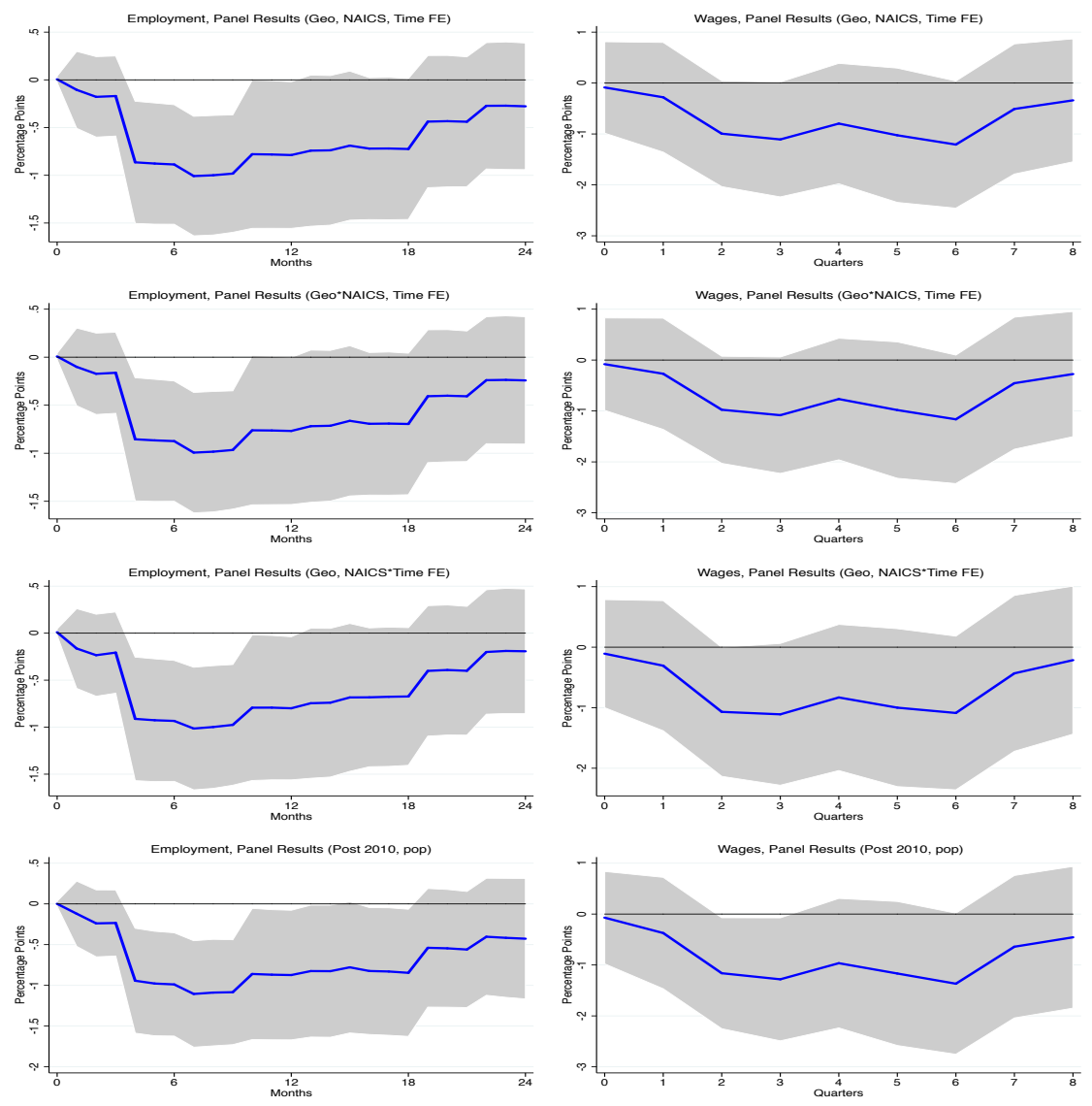
Figure F.2: Employment Effects of Natural Disasters: Strengthened Industries

Figure F.3: Employment Effects of Natural Disasters: Weakened Industries
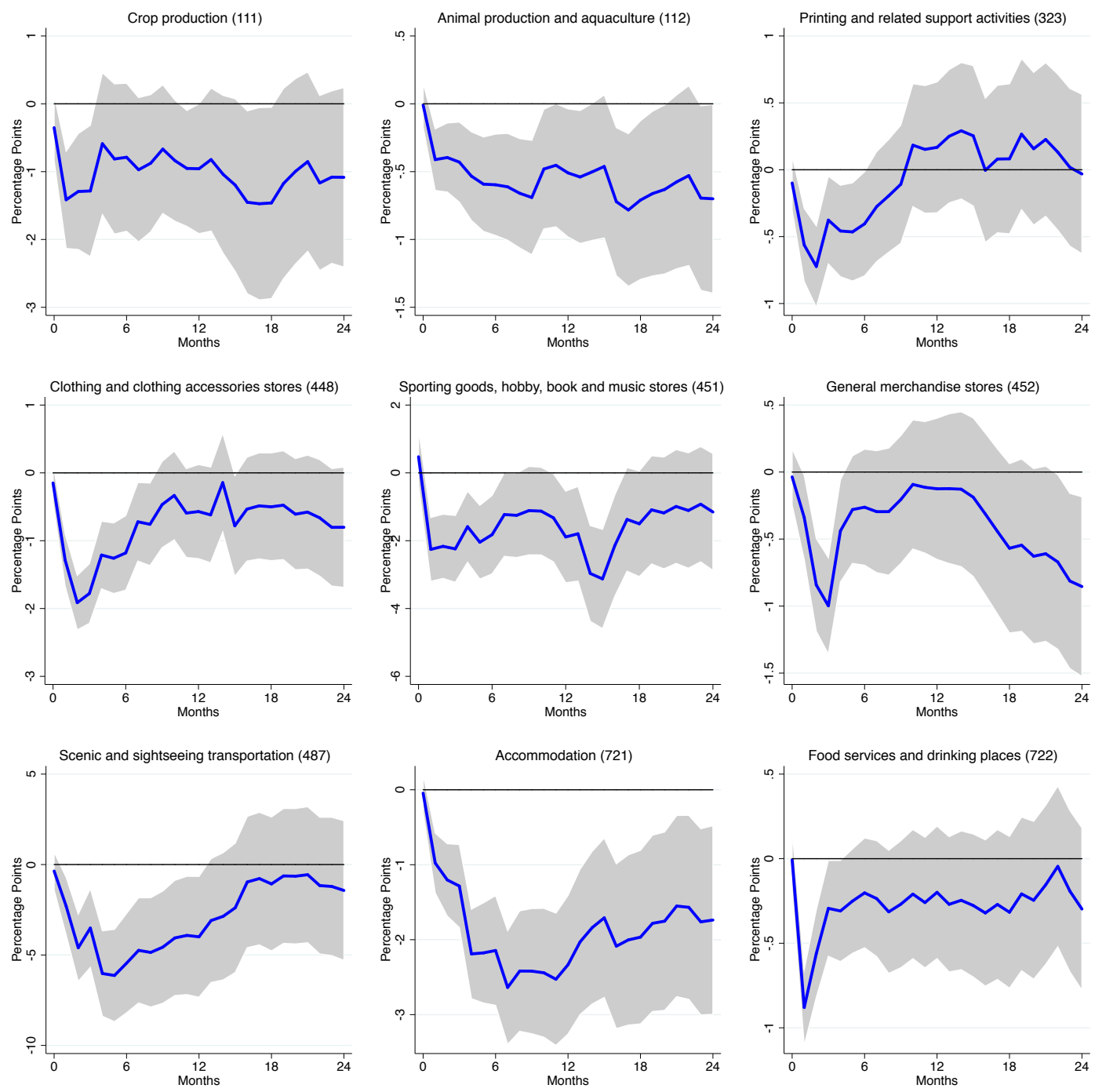
Figure F.4: Employment Effects of Natural Disasters: Neutral Industries
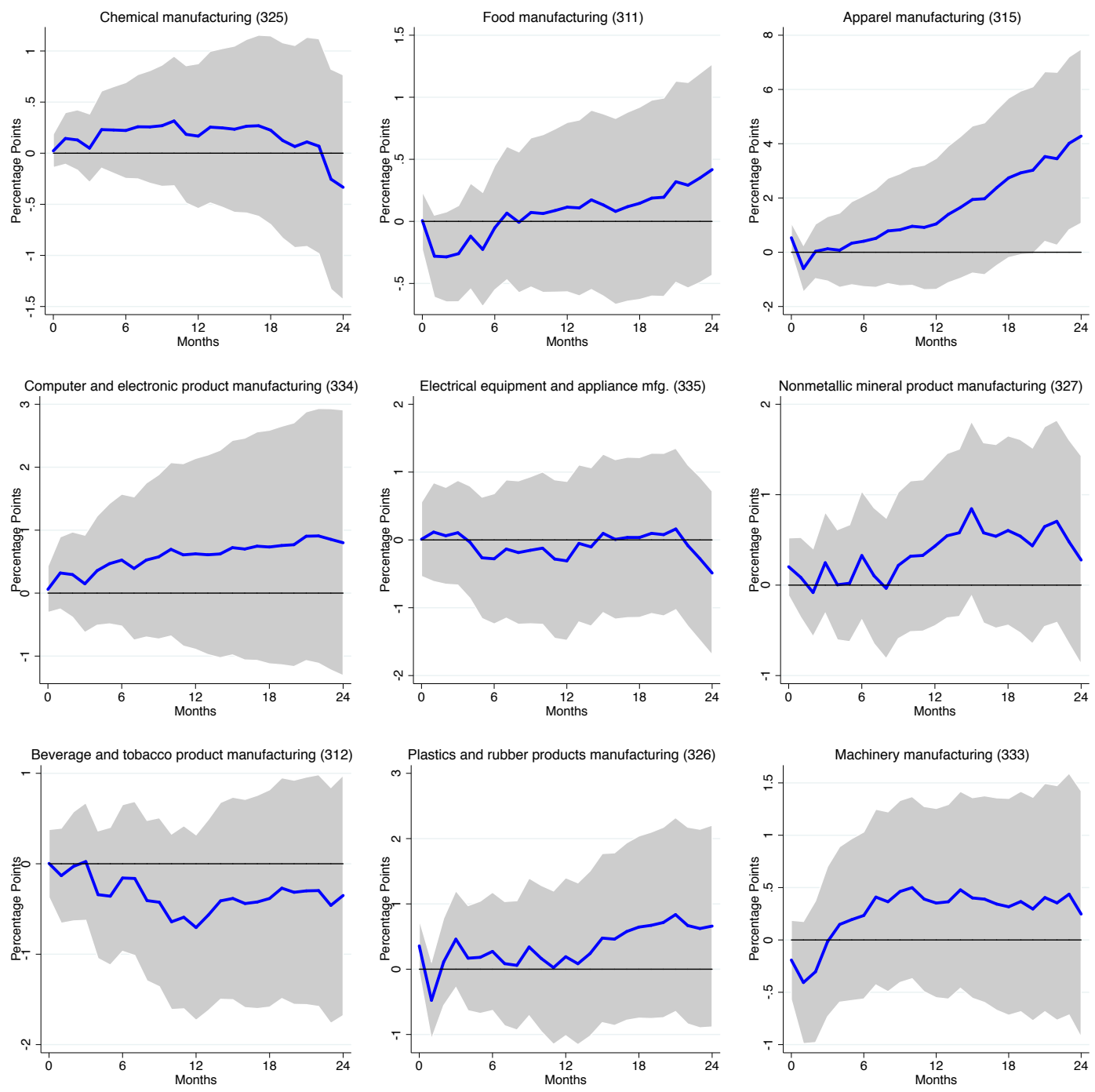


\section{References}

Hsu, S. \& Zhongde, Y. (1998). A Note on the Radius of Maximum Wind for Hurricanes. Journal of Coastal Research, 14(2), 667-668.

Simpson, R. \& Riehl, H. (1981). The Hurricane and Its Impact. Louisiana State University Press. 